\title{
Morphological Characterization of Bipolaris sorokiniana Infecting Wheat
}

\author{
Ankita Biswas* and Srikanta Das \\ Arabindapally, Bagmore, P.O. Kanchrapara, Dist: North-24-Parganas, Pin-743145, \\ West Bengal, India \\ *Corresponding author
}

\section{A B S T R A C T}

\begin{tabular}{|l|}
\hline K e y w o r d s \\
$\begin{array}{l}\text { Bipolaris sorokiniana, } \\
\text { Morphological } \\
\text { characterization, Conidial } \\
\text { structure, Septation, } \\
\text { Spore morphology }\end{array}$ \\
\hline Article Info \\
\hline $\begin{array}{l}\text { Accepted: } \\
\text { 04 July 2018 } \\
\text { Available Online: } \\
\text { 10 August } 2018\end{array}$ \\
\hline
\end{tabular}

Introduction

Wheat (Triticum aestivum L.) is one of the most important grain crops providing nearly $20 \%$ of the total world food requirement (Uddin et al., 2006). It is considered as the second most staple food crop next to rice in India. In India, the contribution of wheat to total food grains production has been ranging between $35-37 \%$ in last 5 years. The contribution of wheat to total food grain is impressive. However, in the background of increasing population, there is a demand for more production of food grains from same piece of land. In order to meet the needs of growing population it will be necessary to produce about $110 \mathrm{~m}$ tons of wheat by 2020
(Swaminathan, 2000) and it is believed that India has the potential to become the largest wheat producer in the world by the end of the year 2020 provided the technological advances in rainfed/drylands are continued with evolution of improved genotypes. The production of wheat in India has improved tremendously with the expansion of high yielding dwarf varieties and better used of inputs.Bipolaris sorokiniana (teleomorph Cochliobolus sativus) is the causal agent of common root rot, leaf spot disease like leaf blotch, seedling blight, head blight, and black point of wheat and barley. The fungus is one of the most important foliar disease constraints for both crops in warmer growing areas and causes significant yield losses. High 
temperature and high relative humidity favour the outbreak of the disease, particularly in South Asia's intensive 'irrigated wheat-rice' production system. In West Bengal as well as all over Eastern India the main important fungal disease is foliar blight caused by Bipolaris sorokiniana and Alternaria triticina may attack singly or together and caused a loss of yield exceeding 60\% (Prabhu and Singh, 1974). The importance of this foliar blight must be expressed in terms of yield losses but an estimate was widely varied according to variety (Nema and Joshi, 1971) assuming significant far and wide in the country. It is apparent from their development that foliar blight may pose a threat to wheat in near future. Considering high yield losses, breeding for resistance demands high priority. It is necessary to have ample genetic variability within the host population. Intensive efforts in many countries are now underway to identify the sources of resistance against foliar blight disease of wheat. As the cultivation of wheat in West Bengal is demanding for increasing food production and farmers are cultivated the crop without knowing the proper cultural practices which decrease the yield by increasing the important disease like foliar blight.

No information has been available regarding the nature of this disease, losses caused by them, epidemiology and management in these agro climatic zones of West Bengal. However, the information on this disease was reported from other parts of the country (Malik et al., 2008, Singh et al., 2003, 2001). But it needs to be constantly improved with regards to several aspects if any safeguard against this risk is to be developed in near future. Different researcher has carried their work on different locations and developed prediction equation for disease forecasting, management (Singh et al., 2004), screening of varieties (Kumar et al., 2010) and others. But in West Bengal condition no information has been available regarding the important pathogens and their variability, causing crop loss, viable and accurate prediction for disease severity and eco-friendly management.

\section{Materials and Methods}

The whole experimental work was carried out with the Bipolaris sorokiniana that were isolated from wheat (Triticum aestivum) and collected from different locations like Old Alluvial Zone (North Bengal), Trans-gangetic plain region, and New Alluvial Zone (Kalyani, Nadia). The morphological studies of the pathogen were conducted on different solid media viz, Potato dextrose agar, carrot agar, oat meal agar, carrot potato agar.

\section{Isolation and identification of the pathogen}

The infected plant parts (leaves) showing typical symptoms of the disease was collected from the field. The standard tissue isolation procedure was followed to isolate the pathogen. The infected tissue with some green portion was surface. sterilized with $0.1 \%$ mercuric chloride $\left(\mathrm{HgCl}_{2}\right)$ for 30 seconds and repeatedly washed separately in sterilized distilled water and then transferred to the sterilized petriplates containing Potato Dextrose Agar (PDA).The petriplates were incubated at room temperature $\left(27 \pm 1{ }^{\circ} \mathrm{C}\right)$ and observed periodically for the growth. Bit of fungal growth developed from the infected tissue was transferred to PDA slants. Then the mycelia tip or single spore isolation was done for purification of the pathogen. Then such pure culture was used for further studies. Identification was done by using microscopes and characters were studied on the basis of their morphological levels.

\section{Maintenance of culture}

All the fungal cultures were maintained in PDA slants and kept in a refrigerator at $5^{\circ} \mathrm{C}$ 
and the cultures were sub-cultured at every 30 days interval regularly or as and when necessary.

Cleaning and sterilization of glass wares and preparation of different media

All the petriplates and another required glass wares were washed thoroughly with detergent powder and running tap water, air dried and wrapped together in a brown paper. Then the glass wares were sterilized in hot air oven at $161^{\circ} \mathrm{C}$ for 2 hours.

\section{Inoculation}

All the petriplates containing different media were inoculated separately with the test fungi (Bipolaris sorokiniana) with the help of inoculating needle aseptically under laminar airflow and kept in a B.O.D incubator at $27 \pm 1$ ${ }^{\circ} \mathrm{C}$ for proper growth of the fungi.

\section{Measurement of radial growth}

After 24 hours of inoculation, radial growth of the fungus was measured by standard millimeter $(\mathrm{mm})$ scale and it was continued every 24 hours interval upto a certain day (s) in each media.

\section{Other morphological studies of the fungus}

For this purpose, the fungus was allowed to grow in Carrot Agar media.

The slides of the selected cultures or colony were prepared in order to study the fungal morphology such as conidial length, breadth, number of septations. The prepared slides were observed under Phase-contrast microscope.

The photographs of the observed conidia are taken and the micrometer measurements of the conidia were done.

\section{Results and Discussion}

Isolation of pathogen and its pathogenicity test

Pathogen was isolated from the infected leaves of wheat from different locations and maintained on PDA through sub- culturing at 15 days intervals. For pathogenecity test, the seeds were sown in perforated aluminium tray containing sterilized potting media (loamy garden soil: compost: weed ash $=65 \mathrm{~kg}$ : $20 \mathrm{~kg}$ : $0.15 \mathrm{~kg}$ ) that was free from infection from any sources. All the pots were kept in glass house and spore suspension containing 5X105 conidia/ml were sprayed on the leaves in evening for observing symptoms. Observation after 10 days interval revealed that in all the sprayed plant produced symptoms like small and dark brown lesion on leaves. The experiment clearly confirms the fact that all the isolates of the fungus Bipolaris sorokiniana can produce the leaf spots (blotch) on wheat.

\section{Morphological variability}

\section{Colony diameter (mm)}

Morphological characters of five representative isolates of Bipolaris sorokiniana including colony size, number of septations of the conidia, length-breadth of conidia were measured on high power (40X) using calibrated filar micrometer and microscope from 10 days old culture on different media and observed that the conidiophores of the fungus were formed singly, straight or flexious, brown to olive brown, the conidia were solitary, straight or slightly flexious and ellipsoidal tapering, pale or olivaceous brown in colour. The different isolates of Bipolaris sorokiniana collected from different locations produces different morphological characters on different media. The results showed that the colony diameter 
(length and Breadth) of different isolates were different and their difference were statistically significant. Different media produces different growth characteristics (Colony diameter) on different media. It was observed that Carrot Agar media produces highest colony diameter (i.e. $48.47 \mathrm{~mm}$ length and $48.00 \mathrm{~mm}$ breadth) whereas minimum in Potato Dextrose Agar media (i.e. $42.61 \mathrm{~mm}$ length, $41.84 \mathrm{~mm}$ breadth) and their difference was statistically significant (Table 1). Here it was also observed that irrespective of the isolates and days after inoculation all the media produces different length and breadth of the colony growth and their difference was statistically significant. Different days after inoculation also produces different growth characteristics (Length-breadth) and with increasing day of inoculation there is significant increase in colony diameter (length-breadth of the isolates) irrespective of isolates and media used. Maximum growth was observed on 7days old culture $(66.94 \mathrm{~mm}$ length and $65.71 \mathrm{~mm}$ breadth) and lowest growth was obtained on 1st days old culture $(12.06 \mathrm{~mm}$ length and $12.07 \mathrm{~mm}$ breadth) (Table 1). Different isolates produces different growths (length and breadth) irrespective of different media and their days of inoculation. It was observed that DWR $\left(\mathrm{I}_{4}\right)$ isolate produces maximum growth $(55.95 \mathrm{~mm}$ length, $55.54 \mathrm{~mm}$ breadth) and minimum was obtained on Kisanganj $\left(\mathrm{I}_{2}\right)$ isolate (i.e. $40.64 \mathrm{~mm}$ length, $39.54 \mathrm{~mm}$ breadth) and their difference was statistically significant irrespective of different media and days after inoculation. It was also observed that isolate Kisanganj and Pundibari showed no significant differences in between them in respect to length and breadth of colony diameter. Medium growth was observed (44.58mm length and $44.39 \mathrm{~mm}$ breadth) was obtained from Kalyani isolate (Length and Breadth) (Table 1). The interaction between media and days after inoculation also showed significant difference among themselves in respect to length and breadth of colony diameter. In every media the colony diameter (length and breadth) is increased significantly with increasing age of growth of the isolates. On Potato Carrot Agar media maximum growth was obtained on 6th day old culture $(60.97 \mathrm{~mm}$ length, $60.25 \mathrm{~mm}$ breadth) whereas in Carrot Agar media (75.04mm length, $74.07 \mathrm{~mm}$ breadth) was also observed on 7 th day old culture which was statistically at par with Oatmeal Agar media on same day old culture (i.e. $73.3 \mathrm{~mm}$ length, $70.82 \mathrm{~mm}$ breadth) and the minimum growth was obtained from PDA media $(57.51 \mathrm{~mm}$ length, $56.80 \mathrm{~mm}$ breadth) irrespective of different isolates. It was observed that 4 th old culture on CA media produces similar growth with that of 5th day old culture of PDA media (Table 1). Similarly, PCA media and PDA media produced same growth of colony diameter (length and breadth) on 1day old culture. It was also observed that 3rd day old culture produces similar type of growth on PCA, CA, OMA whereas PDA media produces highest growth on the same day old culture than the above mentioned media. Interaction between Isolate and different media also produced different growth characteristics and their differences were statistically significant. On PCA media DWR (I4) isolate produces maximum growth (55.74mm length, $54.64 \mathrm{~mm}$ breadth) and minimum by Kisanganj $\left(\mathrm{I}_{2}\right)$ isolate $(39.31 \mathrm{~mm}$ length, $38.23 \mathrm{~mm}$ breadth) and theirdifference was statistically significant, whereas Alipurduar $\left(\mathrm{I}_{1}\right)$ isolate and Pundibari $\left(\mathrm{I}_{3}\right)$ isolate produces similar type of growth, Pundibari isolate $(42.91 \mathrm{~mm}$ length, $43.24 \mathrm{~mm}$ breadth) and Alipurduar isolate $(43.3 \mathrm{~mm}$ length, $43.41 \mathrm{~mm}$ breadth) DWR isolate (I4) also produced maximum growth on CA media. (58.92mm length, $58.86 \mathrm{~mm}$ breadth) and minimum produced by Kisanganj isolate ( $\left.\mathrm{I}_{2}\right)$ (44.1mm length, $42.80 \mathrm{~mm}$ breadth) and their difference was statistically significant. Isolates Pundibari $\left(\mathrm{I}_{3}\right)$ and Kalyani ( $\left.\mathrm{I}_{5}\right)$ produced statistically at par growth 
(Pundibari-47.49mm length; $44.11 \mathrm{~mm}$ breadth) and (Kalyani-47.1mm length; $46.74 \mathrm{~mm}$ breadth) on above mentioned media. Different isolates produced different growth on OMA also. Here Kalyani isolate produced maximum growth on this media. $(50.55 \mathrm{~mm}$ length; $50.30 \mathrm{~mm}$ breadth) and minimum growth was observed on Alipurduar isolate (40.06mm length; $40.16 \mathrm{~mm}$ breadth) and their difference was statistically significant.

On these media Kisanganj and DWR isolate produces similar type of length of colony diameter whereas the breadth of the colony diameter was different in between them (Table 1). Different isolates produced different type of growth on PDA medium also. DWR isolate produces maximum growth $(62.26 \mathrm{~mm}$ length; $61.80 \mathrm{~mm}$ breadth) and minimum was obtained from Pundibari $31.21 \mathrm{~mm}$ length; $30.98 \mathrm{~mm}$ breadth), followed by Kisanganj isolate through their differences are statistically significant. Alipurduar isolate and Kalyani isolate produced similar length of colony growth (Alipurduar I1 $42.11 \mathrm{~mm}$ length; Kalyani $42.83 \mathrm{~mm}$ length) though breadth of their growth was statistically different.

From this above interaction it was observed that DWR isolate produced maximum colony growth on PDA media $(62.26 \mathrm{~mm}$ length; $61.80 \mathrm{~mm}$ breadth) followed by CA media by the same isolate $(58.92 \mathrm{~mm}$ length; $58.86 \mathrm{~mm}$ breadth) and their difference was statistically significant. Minimum growth was obtained from Pundibari isolate on PDA followed by Kisanganj by same media through their difference was statistically significant. Similarly Alipurduar, Kisanganj and Pundibari isolate produced statistically significant. On 1day old culture produced maximum growth by Kalyani isolate $(13.35 \mathrm{~mm}$ length; $13.12 \mathrm{~mm}$ breadth) and minimum by DWR $(10.94 \mathrm{~mm}$ length; $10.68 \mathrm{~mm}$ breadth) though all the isolates showed no significant difference among themselves in respect to their growth on 1day old culture. $2^{\text {nd }}$ day old culture also produced different growth by different isolates. Maximum was obtained from DWR isolate $(28.12 \mathrm{~mm}$ length; $28.83 \mathrm{~mm}$ breadth) and Minimum in (Kisanganj isolate $23.06 \mathrm{~mm}$ length; $22.88 \mathrm{~mm}$ breadth0 statistical at par with Pundibari $(24.17 \mathrm{~mm}$ length; $24.65 \mathrm{~mm}$ breadth).

Though Alipurduar isolate and Kalyani isolate showed no significant difference in between them in respect to length and breadth of colony growth on 2nd day old culture. On 3rd day old culture maximum colony diameter was obtained from DWR isolate $(51.33 \mathrm{~mm}$ length; $51.22 \mathrm{~mm}$ length) and minimum from Pundibari $\quad(34.31 \mathrm{~mm}$ length; $34.36 \mathrm{~mm}$ breadth) statistically at par with Kisanganj though Alipurduar isolate and Kalyani isolate showed no significant difference in between them in respect to their growth on 3 day old culture. DWR isolate also produced maximum growth on 4th day old culture and $66.40 \mathrm{~mm}$ length; $65.8 . \mathrm{mm}$ breadth) whereas minimum growth was obtained from Kisanganj isolate (42.62 $\mathrm{mm}$ length; $41.59 \mathrm{~mm}$ breadth) followed by Pundibari $(43.46 \mathrm{~mm}$ length; $43.26 \mathrm{~mm}$ breadth) though their difference was not statistically significant.

Alipurduar isolate and Kalyani isolate also produce similar type of growth pattern on 4th day culture also. On 5th day old culture maximum growth was also obtained by DWR isolate $(75.22 \mathrm{~mm}$ length; $73.40 \mathrm{~mm}$ breadth) and minimum in Kalyani isolate $(54.98 \mathrm{~mm}$ length; $55.08 \mathrm{~mm}$ breadth) and different was statistically significant. Though the isolates of Alipurduar, Pundibari and Kalyani produced statistically at par results in respect to growth pattern of 5th day old culture. Similar results was also produced on 6th day old culture that DWR isolate showed maximum length and breadth of the growth of the colony $(76.94 \mathrm{~mm}$ length; $76.56 \mathrm{~mm}$ breadth). Here Alipurduar, Kisanganj, Pundibari showed no significance 
among themselves in respect to their growth of colony of 6th day old culture. In 7th day old culture maximum growth was obtained from DWR isolate $(80.75 \mathrm{~mm}$ length; $79.90 \mathrm{~mm}$ breadth) and minimum by Alipurduar isolate and their difference was statistically significant. Though Alipurduar isolate and Pundibari isolate showed no significant difference in between them in respect to their growth on 7th day old culture maximum growth was obtained from DWR isolate (80.75mm length; $79.90 \mathrm{~mm}$ breadth) and minimum by Alipurduar isolate and their difference was statistically significant. Though Alipurduar isolate and Pundibari showed no significant difference in between them in respect to their growth on 7 th day old culture also.

So, it was observed that with increase in the age of the growth of the colony. There is significance increase in length and breadth of the colony structure. Maximum growth was observed on 7th day growth culture irrespective of isolate and DWR isolate produce maximum growth above all isolates. Interaction between media, days and isolates produce different growth characteristics (length and breadth) and difference were statistically significant. All the isolates produced maximum growth in 7th old culture irrespective of media used. Maximum growth was obtained from DWR isolate on CA medium from 7 th day old culture $(85.10 \mathrm{~mm}$ length; $84.73 \mathrm{~mm}$ breadth) statistically at par with same isolate on 6th day old culture of same media and 7th day old culture from PDA media by the same isolate.

It was also observed that DWR is also produced statistically at par growth on 6th day old culture on PDA media and 5thday old culture on PDA media. Minimum growth was obtained from 1st day old culture of OMA media from Alipurduar, Pundibari and DWR isolates $(7.10 \mathrm{~mm}$ length; $9.40 \mathrm{mmbreadth})$; (7.13mm length, $7.1 \backslash \mathrm{mm}$ breadth) and (7.47mm length, $7.73 \mathrm{~mm}$ breadth) respectively (Table 1; Fig. 1, 2 and 5). The analysis of the variances of growth on the basis of length and breadth of the colony of isolates of Bipolaris sorokiniana on different media after different days after inoculation were present in the Table 2 and 3.

\section{Conidial structure (Length)}

Different isolates produced different conidial structure (length and breadth) on different media and their different media and their difference were statistically significant. The length of conidia showed that media plays an significant role in respect to their growth. Maximum length of conidia was obtained on PDA media $(71.33 \mathrm{~mm})$ followed by OMA $(62.43 \mathrm{~mm})$ and difference were statistically significant and minimum length of conidia was obtained on CA media $(38.08 \mathrm{~mm})$ followed by PCA media and difference were statistically significant. When isolates are considered maximum length of conidia was obtained from Alipurduar isolate $(58.65 \mathrm{~mm})$ followed by DWR isolate $(58.52 \mathrm{~mm})$ and Kisanganj isolate $(57.89 \mathrm{~mm})$ and their differences were not statistically significant. Whereas minimum length was obtained from Kalyani $(55.48 \mathrm{~mm})$ isolate statistically at par with Pundibari $(56.45 \mathrm{~mm})$ isolate irrespective of different media. The interaction between Media and Isolate were also produced different conidial structure (length and difference were statistically significant. It was observed that all the isolates produced maximum length of conidia on PDA media and maximum was observed from Alipurduar isolate $(72.19 \mathrm{~mm})$ on PDA media, statistically at par with the Kalyani isolate $(71.88 \mathrm{~mm})$ followed by Pundibari isolate $(71.96 \mathrm{~mm})$ and DWR isolate $(71.21 \mathrm{~mm})$ and their difference were not statistically significant (Table 4; Fig. 3 and 4). 
Table.1 Colony characters analysis of different isolates of Bipolaris sorokiniana in different media

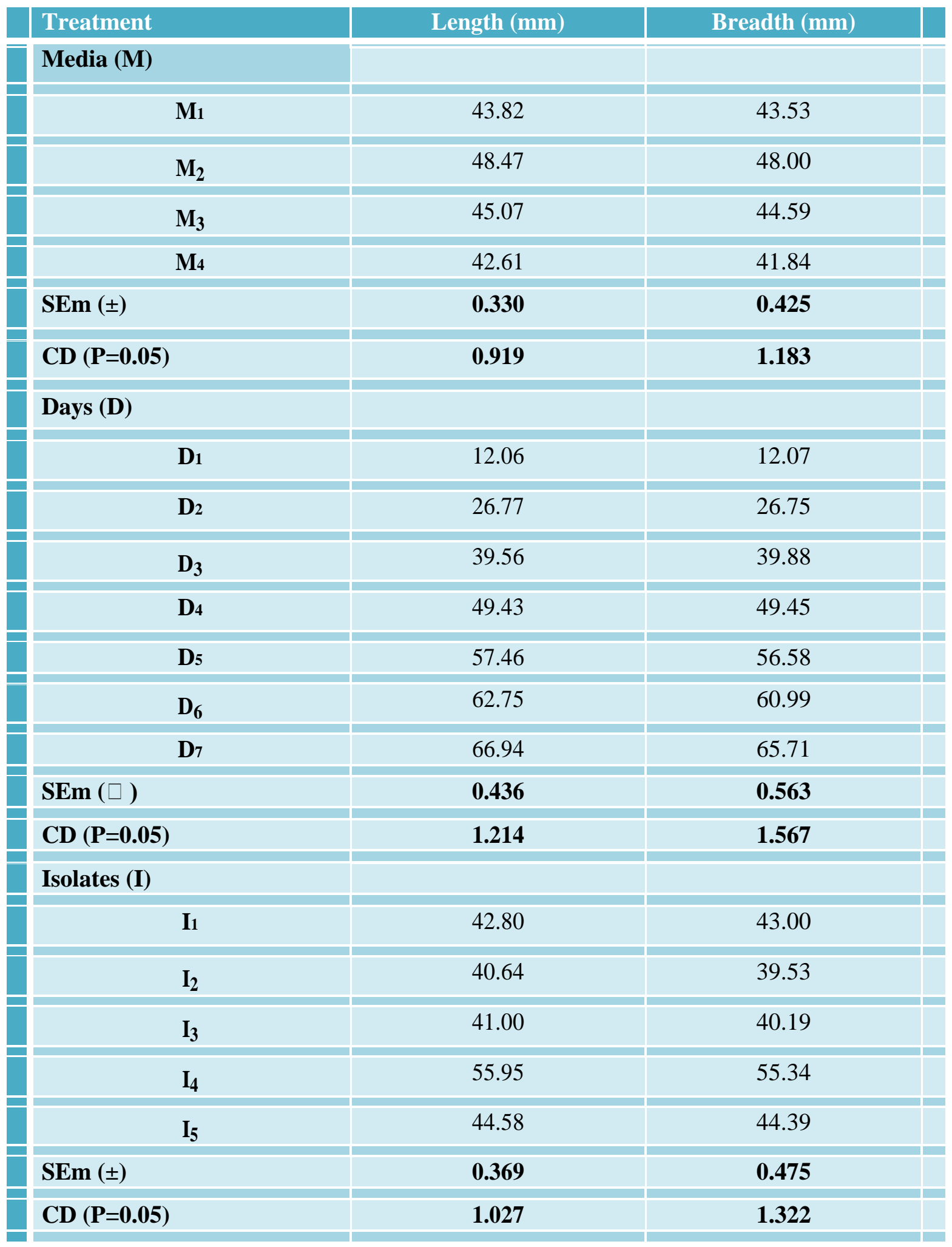


Interaction between media and days after inoculation

\begin{tabular}{|c|c|c|}
\hline Treatment & Length (mm) & Breadth (mm) \\
\hline \multicolumn{3}{|l|}{ Media (M) } \\
\hline $\mathbf{M}$ & 43.82 & 43.53 \\
\hline $\mathbf{M}_{2}$ & 48.47 & 48.00 \\
\hline $\mathbf{M}_{3}$ & 45.07 & 44.59 \\
\hline $\mathbf{M}$ & 42.61 & 41.84 \\
\hline $\operatorname{SEm}( \pm)$ & 0.330 & 0.425 \\
\hline $\mathrm{CD}(\mathrm{P}=\mathbf{0 . 0 5})$ & 0.919 & 1.183 \\
\hline \multicolumn{3}{|l|}{ Days (D) } \\
\hline $\mathbf{D}_{1}$ & 12.06 & 12.07 \\
\hline $\mathbf{D}_{2}$ & 26.77 & 26.75 \\
\hline $\mathbf{D}_{3}$ & 39.56 & 39.88 \\
\hline D & 49.43 & 49.45 \\
\hline Ds & 57.46 & 56.58 \\
\hline$D_{6}$ & 62.75 & 60.99 \\
\hline $\mathbf{D}_{7}$ & 66.94 & 65.71 \\
\hline $\operatorname{SEm}( \pm)$ & 0.436 & 0.563 \\
\hline $\mathrm{CD}(\mathrm{P}=\mathbf{0 . 0 5})$ & 1.214 & 1.567 \\
\hline \multicolumn{3}{|l|}{ Isolates (I) } \\
\hline $\mathbf{I}_{1}$ & 42.80 & 43.00 \\
\hline $\mathbf{I}_{2}$ & 40.64 & 39.53 \\
\hline $\mathbf{I}_{3}$ & 41.00 & 40.19 \\
\hline $\mathrm{I}_{4}$ & 55.95 & 55.34 \\
\hline $\mathbf{I}_{5}$ & 44.58 & 44.39 \\
\hline $\operatorname{SEm}( \pm)$ & 0.369 & 0.475 \\
\hline $\mathrm{CD}(\mathrm{P}=\mathbf{0 . 0 5})$ & 1.027 & 1.322 \\
\hline
\end{tabular}




\section{Interaction between media and isolate}

\begin{tabular}{|c|c|c|}
\hline$(\mathbf{M} \times \mathbf{I})$ & & \\
\hline $\mathbf{M}_{\mathbf{1}} \mathbf{I}_{\mathbf{1}}$ & 43.35 & 43.41 \\
\hline $\mathbf{M}_{1} \mathbf{I}_{2}$ & 39.31 & 38.23 \\
\hline $\mathbf{M}_{1} \mathbf{I}_{3}$ & 42.91 & 43.24 \\
\hline $\mathbf{M}_{1} \mathbf{I}_{4}$ & 55.74 & 54.64 \\
\hline $\mathbf{M}_{1} \mathbf{I}_{5}$ & 37.80 & 38.10 \\
\hline $\mathbf{M}_{2} \mathbf{I}_{1}$ & 44.69 & 47.50 \\
\hline $\mathrm{M}_{2} \mathbf{I}_{2}$ & 44.11 & 42.80 \\
\hline $\mathbf{M}_{\mathbf{2}} \mathbf{I}_{\mathbf{3}}$ & 47.49 & 44.11 \\
\hline $\mathbf{M}_{2} \mathbf{I}_{4}$ & 58.92 & 58.86 \\
\hline $\mathbf{M}_{2} \mathbf{I}_{\mathbf{5}}$ & 47.15 & 46.74 \\
\hline M3/1 & 41.06 & 41.16 \\
\hline $\mathbf{M} \mathbf{I}_{2}$ & 44.49 & 43.01 \\
\hline$\overline{M_{3} I_{3}}$ & 42.38 & 42.43 \\
\hline $\mathrm{M}_{3} \mathrm{I}_{4}$ & 46.88 & 46.04 \\
\hline $\mathrm{M}_{\mathbf{3}} \mathbf{I}_{5}$ & 50.55 & 50.30 \\
\hline $\mathbf{M}_{\mathbf{4}} \mathbf{I}_{\mathbf{1}}$ & 42.11 & 39.94 \\
\hline $\mathbf{M}_{4} \mathbf{I}_{2}$ & 34.64 & 34.06 \\
\hline $\mathbf{M}_{\mathbf{4}} \mathbf{I}_{\mathbf{3}}$ & 31.21 & 30.98 \\
\hline $\mathbf{M}_{4} \mathbf{I}_{4}$ & 62.26 & 61.80 \\
\hline $\mathbf{M}_{4} \mathbf{I}_{5}$ & 42.83 & 42.41 \\
\hline $\operatorname{SEm}( \pm)$ & 0.737 & 0.591 \\
\hline $\mathrm{CD}(\mathrm{P}=\mathbf{0 . 0 5})$ & 2.052 & 1.645 \\
\hline
\end{tabular}


Interaction between days after inoculation and isolates

\begin{tabular}{|c|c|c|}
\hline$(\mathrm{D} \times \mathrm{I})$ & & \\
\hline \multirow[t]{2}{*}{ D1I1 } & & \\
\hline & 13.19 & 13.87 \\
\hline \multirow[t]{2}{*}{$\mathbf{D}_{1} \mathbf{I}_{2}$} & & \\
\hline & 11.17 & 10.93 \\
\hline D1I3 & 11.66 & 11.73 \\
\hline \multirow{2}{*}{$\mathbf{D}_{1} \mathbf{I}_{4}$} & & \\
\hline & 10.94 & 10.68 \\
\hline D1I5 & 13.35 & 13.12 \\
\hline \multirow[t]{2}{*}{$\mathbf{D}_{\mathbf{2}} \mathbf{I}_{1}$} & & \\
\hline & 28.61 & 28.83 \\
\hline D2I2 & 23.06 & 22.88 \\
\hline \multirow[t]{2}{*}{$\mathbf{D}_{2} \mathbf{I}_{3}$} & & \\
\hline & 24.17 & 24.65 \\
\hline D2I4 & 30.07 & 29.71 \\
\hline \multirow[t]{2}{*}{$\mathbf{D}_{2} \mathbf{I}_{5}$} & & \\
\hline & 27.93 & 27.67 \\
\hline D3I1 & 39.04 & 40.09 \\
\hline \multirow{2}{*}{$\mathbf{D}_{3} \mathbf{I}_{2}$} & & \\
\hline & 34.43 & 33.93 \\
\hline $\mathbf{D}_{\mathbf{3}} \mathbf{I}_{\mathbf{3}}$ & 34.31 & 34.36 \\
\hline $\mathbf{D}_{3} \mathbf{I}_{4}$ & 51.33 & 51.22 \\
\hline D3I5 & 38.66 & 39.81 \\
\hline \multirow[t]{2}{*}{$\mathbf{D}_{4} \mathbf{I}_{1}$} & & \\
\hline & 47.14 & 48.63 \\
\hline $\mathbf{D}_{\mathbf{4}} \mathbf{I}_{2}$ & 42.62 & 41.59 \\
\hline $\mathbf{D}_{4} \mathbf{I}_{3}$ & 43.46 & 43.62 \\
\hline $\mathbf{D}_{4} \mathbf{I}_{4}$ & 66.40 & 65.88 \\
\hline $\mathbf{D}_{4} \mathbf{I}_{5}$ & 47.52 & 47.54 \\
\hline $\mathbf{D}_{5} \mathbf{I}_{1}$ & 54.04 & 53.48 \\
\hline $\mathbf{D}_{5} \mathbf{I}_{2}$ & 49.68 & 48.43 \\
\hline $\mathbf{D}_{5} \mathbf{I}_{3}$ & 53.37 & 52.49 \\
\hline $\mathbf{D}_{5} \mathbf{I}_{4}$ & 75.22 & 73.40 \\
\hline $\mathbf{D}_{5} \mathbf{I}_{5}$ & 54.98 & 55.08 \\
\hline $\mathbf{D}_{6} \mathbf{I}_{1}$ & 57.15 & 57.24 \\
\hline $\mathbf{D}_{6} \mathbf{I}_{2}$ & 58.95 & 57.04 \\
\hline $\mathbf{D}_{6} \mathbf{I}_{3}$ & 58.24 & 53.12 \\
\hline$D_{6} I_{4}$ & 76.94 & 76.57 \\
\hline $\mathbf{D}_{6} \mathbf{I}_{5}$ & 62.48 & 60.97 \\
\hline $\mathbf{D}_{7} \mathbf{I}_{1}$ & 60.44 & 58.89 \\
\hline $\mathbf{D}_{7} \mathbf{I}_{2}$ & 64.55 & 61.86 \\
\hline $\mathbf{D}_{7} \mathbf{I}_{3}$ & 61.78 & 61.37 \\
\hline $\mathbf{D}_{7} \mathbf{I}_{4}$ & 80.75 & 79.90 \\
\hline $\mathbf{D}_{7} \mathbf{I}_{5}$ & 67.17 & 66.53 \\
\hline SEm $( \pm)$ & 0.976 & 1.258 \\
\hline $\mathrm{CD}(\mathrm{P}=0.05)$ & 2.717 & 3.502 \\
\hline
\end{tabular}


Interaction between media, days after inoculation an isolates

\begin{tabular}{|c|c|c|}
\hline$(\mathrm{M} \times \mathrm{D} \times \mathrm{I})$ & & \\
\hline $\mathbf{M}_{1} \mathbf{D}_{1} \mathbf{I}_{1}$ & 15.67 & 15.70 \\
\hline $\mathbf{M}_{1} \mathbf{D}_{1} \mathbf{I}_{2}$ & 12.37 & 12.03 \\
\hline $\mathbf{M}_{1} \mathbf{D}_{1} \mathbf{I}_{3}$ & 13.67 & 13.40 \\
\hline $\mathrm{M}_{1} \mathrm{D}_{1} \mathrm{I}_{4}$ & 11.07 & 10.00 \\
\hline $\mathrm{M}_{1} \mathrm{D}_{1} \mathrm{I}_{5}$ & 14.43 & 13.37 \\
\hline $\mathbf{M}_{1} \mathbf{D}_{2} \mathbf{I}_{1}$ & 29.67 & 30.00 \\
\hline M1D2I2 & 21.37 & 22.00 \\
\hline $\mathbf{M}_{1} \mathbf{D}_{2} \mathbf{I}_{3}$ & 26.47 & 26.70 \\
\hline $\mathbf{M}_{1} \mathbf{D}_{2} \mathbf{I}_{4}$ & 29.17 & 28.37 \\
\hline $\mathbf{M}_{1} \mathbf{D}_{2} \mathbf{I}_{5}$ & 27.47 & 25.70 \\
\hline $\mathbf{M}_{1} \mathbf{D}_{3} \mathbf{I}_{1}$ & 38.40 & 39.37 \\
\hline $\mathbf{M}_{1} \mathbf{D}_{3} \mathbf{I}_{2}$ & 31.43 & 32.53 \\
\hline M1D3I3 & 34.83 & 34.47 \\
\hline M1D3I4 & 48.73 & 48.77 \\
\hline $\mathbf{M}_{1} \mathbf{D}_{3} \mathbf{I}_{5}$ & 34.80 & 37.73 \\
\hline $\mathbf{M}_{1} \mathbf{D}_{4} \mathbf{I}_{1}$ & 47.10 & 49.10 \\
\hline M1D4I2 & 44.57 & 39.50 \\
\hline $\mathbf{M}_{1} \mathbf{D}_{4} \mathbf{I}_{3}$ & 47.20 & 47.73 \\
\hline $\mathbf{M}_{1} \mathbf{D}_{4} \mathbf{I}_{4}$ & 64.43 & 65.67 \\
\hline $\mathrm{M}_{1} \mathrm{D}_{4} \mathrm{I}_{5}$ & 41.53 & 43.00 \\
\hline M1D5I1 & 53.10 & 53.03 \\
\hline $\mathbf{M}_{1} \mathbf{D}_{5} \mathbf{I}_{2}$ & 45.13 & 47.10 \\
\hline $\mathrm{M}_{1} \mathrm{D}_{5} \mathrm{I}_{3}$ & 57.10 & 56.33 \\
\hline $\mathbf{M}_{1} \mathbf{D}_{5} \mathbf{I}_{4}$ & 83.07 & 77.60 \\
\hline $\mathrm{M}_{1} \mathrm{D}_{5} \mathrm{I}_{5}$ & 46.83 & 47.33 \\
\hline M1D6I1 & 58.17 & 58.03 \\
\hline $\mathbf{M}_{1} \mathbf{D}_{6} \mathbf{I}_{2}$ & 59.20 & 56.73 \\
\hline $\mathbf{M}_{1} \mathbf{D}_{6} \mathbf{I}_{3}$ & 61.07 & 62.00 \\
\hline M1D6I4 & 76.53 & 74.67 \\
\hline $\mathbf{M}_{1} \mathbf{D}_{6} \mathbf{I}_{5}$ & 49.90 & 49.83 \\
\hline $\mathbf{M}_{1} \mathbf{D}_{7} \mathbf{I}_{1}$ & 61.33 & 58.67 \\
\hline M1D7I2 & 61.10 & 57.73 \\
\hline $\mathbf{M}_{1} \mathbf{D}_{7} \mathbf{I}_{3}$ & 60.07 & 62.03 \\
\hline $\mathbf{M}_{1} \mathbf{D}_{7} \mathbf{I}_{4}$ & 77.17 & 77.40 \\
\hline $\mathbf{M}_{1} \mathbf{D}_{7} \mathbf{I}_{5}$ & 49.60 & 49.73 \\
\hline M2D1I1 & 13.10 & 13.73 \\
\hline $\mathbf{M}_{2} \mathrm{D}_{1} \mathbf{I}_{2}$ & 10.70 & 10.03 \\
\hline $\mathbf{M}_{2} \mathbf{D}_{1} \mathbf{I}_{3}$ & 13.40 & 13.00 \\
\hline $\mathbf{M}_{2} \mathbf{D}_{1} \mathbf{I}_{4}$ & 13.43 & 13.00 \\
\hline
\end{tabular}


Int.J.Curr.Microbiol.App.Sci (2018) 7(8): 225-248

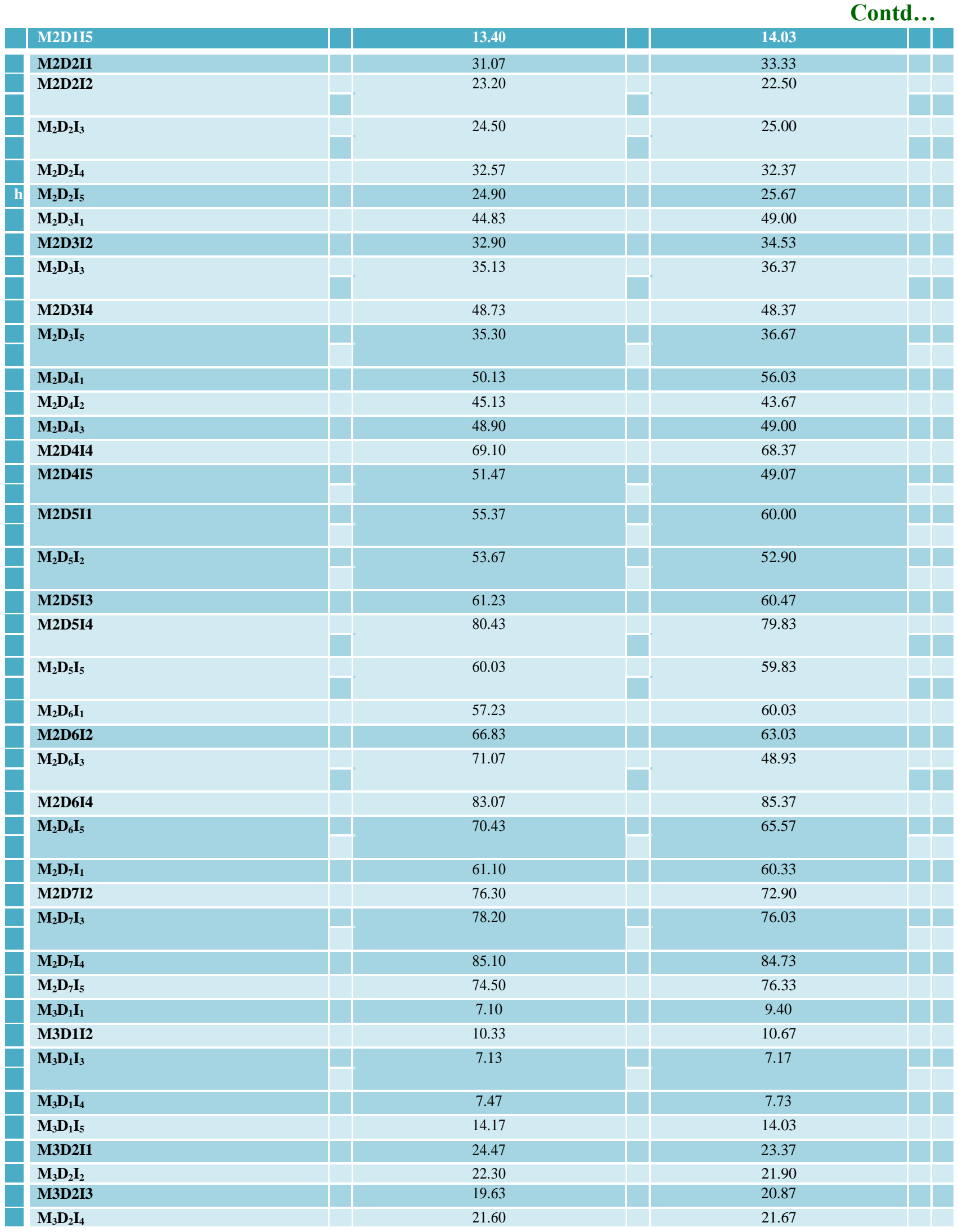


Contd....

\begin{tabular}{|c|c|c|c|}
\hline M3D2I5 & 30.10 & 30.67 & \\
\hline M3D3I1 & 34.67 & 34.53 & 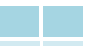 \\
\hline M3D3I2 & 35.57 & 33.53 & \\
\hline $\mathbf{M}_{3} \mathbf{D}_{3} \mathbf{I}_{3}$ & 35.40 & 34.87 & \\
\hline $\mathrm{M}=\mathrm{D}_{2} \mathrm{.}$ & 1080 & 1070 & \\
\hline & & 5 & \\
\hline $\mathrm{M}_{3} \mathrm{U}_{3} \mathbf{1}_{5}$ & & 43.13 & \\
\hline $\mathbf{M}_{3} \mathbf{D}_{4} \mathbf{I}_{1}$ & 43.77 & 45.33 & \\
\hline M3D4I2 & 42.20 & 44.33 & \\
\hline $\mathbf{M}_{3} \mathbf{D}_{4} \mathbf{I}_{3}$ & 42.33 & 43.00 & \\
\hline M3D4I4 & 54.80 & 53.63 & \\
\hline $\mathbf{M}_{3} \mathbf{D}_{4} \mathbf{I}_{5}$ & 54.87 & 55.43 & \\
\hline $\mathbf{M}_{3} \mathbf{D}_{5} \mathbf{I}_{1}$ & 54.00 & 53.97 & \\
\hline $\mathbf{M}_{3} \mathbf{D}_{5} \mathbf{I}_{2}$ & 59.37 & 53.50 & \\
\hline $\mathbf{M}_{3} \mathbf{D}_{5} \mathbf{I}_{3}$ & 58.23 & 57.50 & \\
\hline M3D5I4 & 58.17 & 57.37 & \\
\hline M3D5I5 & 62.40 & 62.70 & 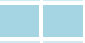 \\
\hline M3D6I1 & 58.57 & 58.50 & \\
\hline $\mathbf{M}_{3} \mathbf{D}_{6} \mathbf{I}_{2}$ & 66.17 & 65.00 & \\
\hline M3D6I3 & 63.20 & 64.33 & \\
\hline M3D6I4 & 68.10 & 66.20 & \\
\hline $\mathbf{M}_{3} \mathbf{D}_{6} \mathbf{I}_{5}$ & 69.97 & 69.47 & \\
\hline & & & \\
\hline $\mathbf{M}_{3} \mathbf{D}_{7} \mathbf{I}_{1}$ & 64.87 & 63.03 & \\
\hline M3D7/2 & 75.50 & 72.13 & \\
\hline $\mathbf{M}_{3} \mathbf{D}_{7} \mathbf{I}_{3}$ & 70.70 & 69.27 & \\
\hline M3D7I4 & 77.23 & 75.00 & \\
\hline $\mathbf{M}_{3} \mathbf{D}_{7} \mathbf{I}_{5}$ & 78.47 & 74.67 & \\
\hline $\mathbf{M}_{4} \mathbf{D}_{1} \mathbf{I}_{1}$ & 16.90 & 16.63 & \\
\hline M4D1I2 & 11.27 & 11.00 & \\
\hline $\mathbf{M}_{4} \mathbf{D}_{1} \mathbf{I}_{3}$ & 12.43 & 13.37 & \\
\hline $\mathbf{M}_{4} \mathbf{D}_{1} \mathbf{I}_{4}$ & 11.80 & 12.00 & \\
\hline $\mathbf{M}_{4} \mathbf{D}_{1} \mathbf{I}_{5}$ & 11.40 & 11.03 & \\
\hline $\mathbf{M}_{4} \mathbf{D}_{2} \mathbf{I}_{1}$ & 29.23 & 28.63 & \\
\hline M4D2I2 & 25.37 & 25.13 & \\
\hline $\mathbf{M}_{4} \mathbf{D}_{2} \mathbf{I}_{3}$ & 26.07 & 26.03 & \\
\hline $\mathbf{M}_{4} \mathbf{D}_{2} \mathbf{I}_{4}$ & 36.93 & 36.43 & \\
\hline $\mathbf{M}_{4} \mathbf{D}_{2} \mathbf{I}_{5}$ & 29.23 & 28.63 & \\
\hline M4D3I1 & 38.27 & 37.47 & \\
\hline $\mathbf{M}_{4} \mathbf{D}_{3} \mathbf{I}_{2}$ & 37.83 & 35.13 & \\
\hline M4D3I3 & 31.87 & 31.73 & \\
\hline $\mathbf{M}_{4} \mathbf{D}_{3} \mathbf{I}_{\mathbf{4}}$ & 67.07 & 67.03 & \\
\hline
\end{tabular}


Contd....

\begin{tabular}{|c|c|c|}
\hline M4D3I5 & 40.63 & 39.70 \\
\hline $\mathrm{M}_{4} \mathrm{D}_{4} \mathbf{I}_{1}$ & 47.57 & 44.03 \\
\hline $\mathrm{M}_{4} \mathrm{D}_{4} \mathrm{I}_{2}$ & 38.57 & 38.87 \\
\hline $\mathbf{M}_{4} \mathbf{D}_{4} \mathbf{I}_{3}$ & 35.40 & 34.73 \\
\hline $\mathbf{M}_{4} \mathbf{D}_{4} \mathbf{I}_{4}$ & 77.27 & 75.83 \\
\hline $\mathbf{M}_{4} \mathbf{D}_{4} \mathbf{I}_{5}$ & 42.20 & 42.67 \\
\hline$M_{4} D_{5} I_{1}$ & 53.70 & 46.90 \\
\hline $\mathrm{M}_{4} \mathrm{D}_{5} \mathrm{I}_{2}$ & 40.53 & 40.23 \\
\hline $\mathrm{M}_{4} \mathrm{D}_{5} \mathbf{I}_{3}$ & 36.90 & 35.67 \\
\hline $\mathrm{M}_{4} \mathrm{D}_{5} \mathrm{I}_{4}$ & 79.20 & 78.80 \\
\hline $\mathbf{M}_{4} \mathbf{D}_{\mathbf{5}} \mathbf{I}_{\mathbf{5}}$ & 50.67 & 50.43 \\
\hline $\mathbf{M}_{4} \mathbf{D}_{6} \mathbf{I}_{1}$ & 54.63 & 52.40 \\
\hline $\mathbf{M}_{4} \mathbf{D}_{6} \mathbf{I}_{2}$ & 43.60 & 43.40 \\
\hline $\mathbf{M}_{4} \mathbf{D}_{6} \mathbf{I}_{3}$ & 37.63 & 37.20 \\
\hline $\mathrm{M}_{4} \mathrm{D}_{6} \mathrm{I}_{4}$ & 80.07 & 80.03 \\
\hline M4D6I5 & 59.60 & 59.00 \\
\hline $\mathbf{M}_{4} \mathrm{D}_{7} \mathbf{I}_{1}$ & 54.47 & 53.53 \\
\hline $\mathbf{M}_{4} \mathbf{D}_{7} \mathbf{I}_{2}$ & 45.30 & 44.67 \\
\hline $\mathbf{M}_{4} \mathbf{D}_{7} \mathbf{I}_{3}$ & 38.17 & 38.13 \\
\hline $\mathrm{M}_{4} \mathrm{D}_{7} \mathbf{I}_{4}$ & 83.50 & 82.47 \\
\hline $\mathbf{M}_{4} \mathrm{D}_{7} \mathbf{I}_{5}$ & 66.10 & 65.40 \\
\hline $\operatorname{SEm}( \pm)$ & 1.591 & 2.516 \\
\hline $\mathrm{CD}(\mathrm{P}=0.05)$ & 4.429 & 7.004 \\
\hline
\end{tabular}

\begin{tabular}{|l|l|l|l|l|l|}
\hline $\mathbf{M}_{1}$ & Potato Carrot Agar & $\mathbf{D}_{1}$ & day1 & $\mathbf{I}_{\mathbf{1}}$ & Alipurduar \\
\hline $\mathbf{M}_{2}$ & Carrot Agar & $\mathbf{D}_{\mathbf{2}}$ & day2 & $\mathbf{I}$ & Kisanganj \\
\hline $\mathbf{M}_{3}$ & Oatmeal Agar & $\mathbf{D}_{\mathbf{3}}$ & day3 & $\mathbf{2}$ & \\
\hline $\mathbf{M}_{4}$ & Potato Dextrose Agar & $\mathbf{D}_{\mathbf{4}}$ & day4 & $\mathbf{I}_{\mathbf{3}}$ & Pundibari \\
\hline & & $\mathbf{D}_{\mathbf{5}}$ & day5 & $\mathbf{I}_{\mathbf{4}}$ & DWR \\
\hline & $\mathbf{D}_{\mathbf{6}}$ & day6 & $\mathbf{I}_{\mathbf{5}}$ & Kalyani \\
\hline & $\mathbf{D}_{\mathbf{7}}$ & day7 & & \\
\hline & & & & & \\
\hline
\end{tabular}


Table.2 Analysis of variance of growth (length) of colony of isolates of Bipolari sorokiniana on different media after different days after inoculation

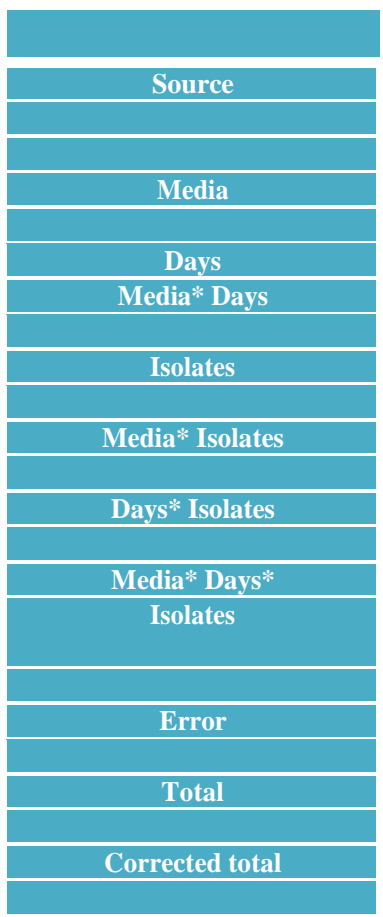

\begin{tabular}{|c|c|c|c|c|}
\hline Type III & & & & \\
\hline Sum of & df & Mean Square & $\mathbf{F}$ & Sig. \\
\hline \multicolumn{5}{|l|}{ Squares } \\
\hline & & & & \\
\hline 2010.672 & 3 & 670.224 & 58.685 & 0.000 \\
\hline 145096.369 & 6 & 24182.728 & $2.117 \mathrm{E}^{3}$ & 0.000 \\
\hline 4778.207 & 18 & 265.456 & 22.243 & 0.000 \\
\hline 13437.688 & 4 & 3359.422 & 294.150 & 0.000 \\
\hline 7183.695 & 12 & 598.641 & 52.417 & 0.000 \\
\hline 5248.580 & 24 & 218.691 & 19.149 & 0.000 \\
\hline 4260.028 & 70 & 59.167 & 5.181 & 0.000 \\
\hline 3197.813 & 280 & 11.421 & - & - \\
\hline 1035470.070 & 420 & - & - & - \\
\hline 185213.053 & 490 & - & - & - \\
\hline
\end{tabular}

Table.3 Analysis of variance of growth (breadth) of colony of isolates of Bipolaris sorokiniana on different media after different days after inoculation

\begin{tabular}{|c|c|c|c|c|c|}
\hline & Type III & df & Mean Square & $\mathbf{F}$ & Sig. \\
\hline Source & Sum of & & & & \\
\hline & Squares & & & & \\
\hline Corrected Model & $173033.353^{\mathrm{a}}$ & 139 & 1244.844 & 65.556 & 0.000 \\
\hline Intercept & 831268.957 & 1 & 831268.957 & $4.378 \mathrm{E}^{4}$ & 0.000 \\
\hline Media & 2131.051 & 3 & 710.350 & 37.408 & 0.000 \\
\hline Days & 136821.194 & 6 & 2283.532 & $1.201 \mathrm{E}^{3}$ & 0.000 \\
\hline Media* Days & 3820.893 & 18 & 212.272 & 11.179 & 0.000 \\
\hline Isolates & 13690.886 & 4 & 3422.721 & 180.247 & 0.000 \\
\hline Media* Isolates & 6835.008 & 12 & 569.584 & 29.995 & 0.000 \\
\hline Days* Isolates & 5504.759 & 24 & 229.365 & 12.079 & 0.000 \\
\hline Media* Days* & \multirow[t]{2}{*}{4229.562} & 72 & \multirow[t]{2}{*}{58.7744} & \multirow[t]{2}{*}{3.094} & 0.000 \\
\hline \multicolumn{3}{|l|}{ Isolates } & & & \\
\hline Error & 5316.940 & 280 & 18.989 & - & - \\
\hline Total & 1009619.250 & 420 & - & - & - \\
\hline hujCorrected total & 178350.293 & 490 & - & - & - \\
\hline
\end{tabular}


Table.4 Morphological structure (length of conidia in $\mu \mathrm{m}$ ) of different isolates of Bipolaris sorokiniana on different growth media

\begin{tabular}{|c|c|c|c|c|c|}
\hline Media (M) & & & & & \\
\hline Isolates & $\mathbf{M}_{1}$ & $\mathbf{M}_{2}$ & $\mathbf{M}_{3}$ & M & Mean \\
\hline \multicolumn{6}{|l|}{ (I) $\mathrm{AL}$} \\
\hline$I_{1}$ & 61.23 & 61.76 & 39.42 & 72.19 & 58.65 \\
\hline $\mathbf{I}_{2}$ & 66.82 & 62.69 & 33.36 & 71.21 & $\mathbf{5 8 . 5 2}$ \\
\hline $\mathbf{I}_{3}$ & 57.41 & 62.42 & 34.01 & 71.96 & 56.45 \\
\hline & & & & & \\
\hline $\mathrm{I}_{4}$ & 59.92 & 61.82 & 40.42 & 69.41 & $\mathbf{5 7 . 8 9}$ \\
\hline$I_{5}$ & 43.42 & 63.47 & 43.17 & 71.88 & 55.48 \\
\hline Mean & 57.76 & 62.43 & 38.08 & 71.33 & \\
\hline & & & & & \\
\hline & Media (M) & & Isolates (I) & & $\mathbf{M} \times \mathbf{I}$ \\
\hline SEm ( \pm$)$ & 0.411 & & 0.459 & & 0.918 \\
\hline $\mathrm{CD}(\mathrm{P}=0.05)$ & 1.144 & & 1.278 & & 2.556 \\
\hline
\end{tabular}

Table.5 Morphological structure (breadth of conidia in $\mu \mathrm{m}$ ) of different isolates of Bipolaris sorokiniana on different growth media

\begin{tabular}{|c|}
\hline Media (M) \\
\hline Isolates (I) \\
\hline $\mathrm{I}_{\mathbf{1}}$ \\
\hline $\mathrm{I}_{\mathbf{2}}$ \\
\hline $\mathrm{I}_{\mathbf{3}}$ \\
\hline $\mathrm{I}_{\mathbf{4}}$ \\
\hline $\mathrm{I}_{\mathbf{5}}$ \\
\hline $\mathrm{Mean}$ \\
\hline $\mathrm{Mem}( \pm)$ \\
\hline SD $(\mathbf{P}=\mathbf{0 . 0 5})$ \\
\hline
\end{tabular}

\begin{tabular}{|c|c|c|c|c|}
\hline $\mathbf{M}_{1}$ & $\mathbf{M}_{2}$ & $\mathbf{M}_{3}$ & $\mathbf{M}_{4}$ & Mean \\
\hline 22.80 & 22.64 & 21.88 & 21.20 & 22.13 \\
\hline 18.28 & 17.80 & 21.75 & 22.05 & 19.97 \\
\hline 18.71 & 19.97 & 18.65 & 21.66 & 19.75 \\
\hline 20.11 & 21.67 & 21.21 & 21.18 & 21.04 \\
\hline 14.64 & 21.81 & 20.17 & 20.69 & 19.33 \\
\hline 18.91 & 20.78 & 20.73 & 21.35 & \\
\hline Media (M) & & Isolates (I) & & $\mathbf{M} \times \mathbf{I}$ \\
\hline 0.253 & & 0.282 & & 0.565 \\
\hline 0.704 & & 0.785 & & 1.573 \\
\hline
\end{tabular}


Table.6 Morphological structure (septations conidia) of different isolates of Bipolaris sorokiniana on different growth media

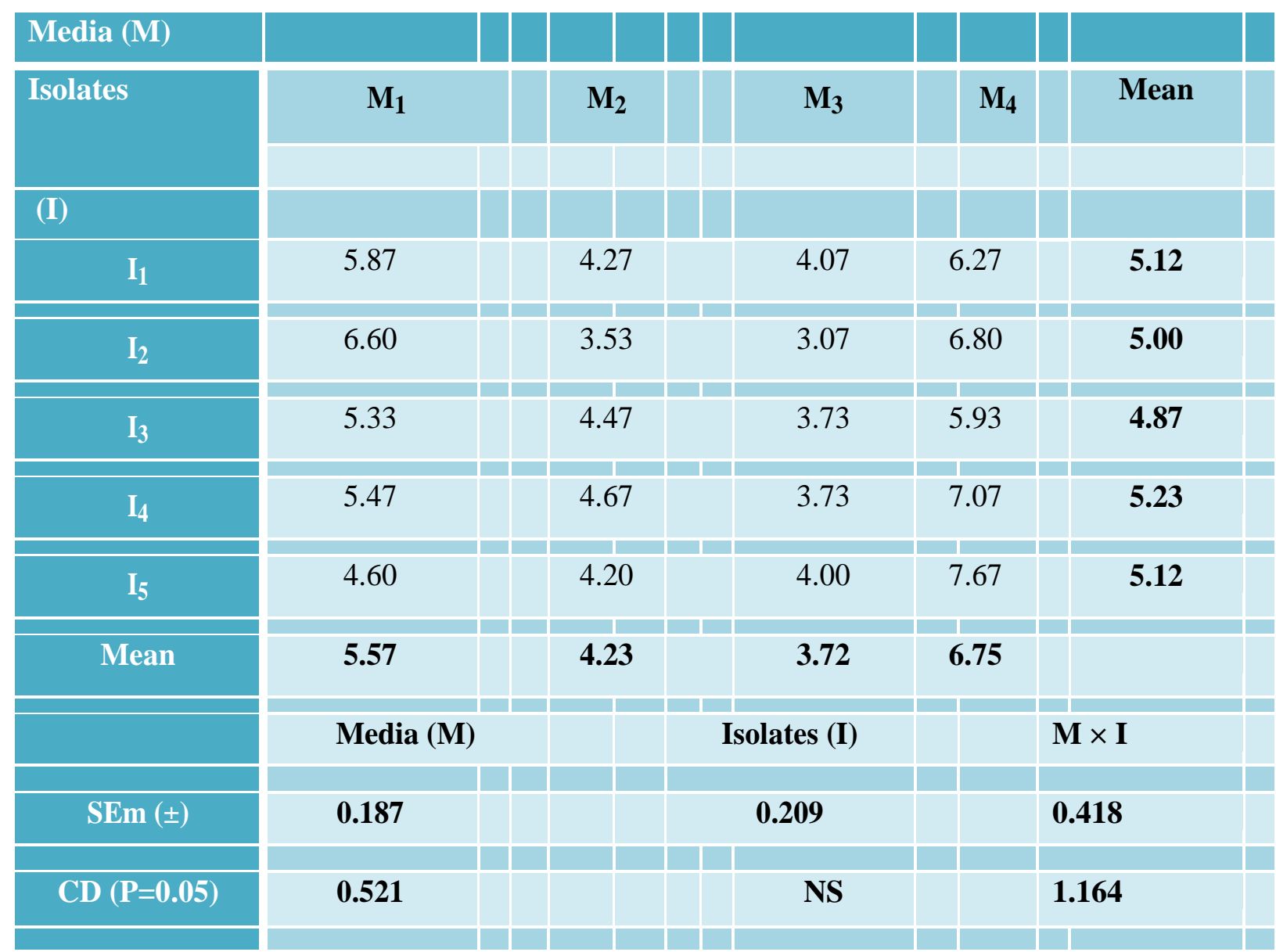

Fig.1 (a) Cochliobolus sativus tritici (b) Cochliobolus leaf spot caused by Bipolaris sorokiniana. (c) Typical symptoms of leaf blotch caused by Bipolaris sorokiniana. (d) Dark discolouration on infected subcrown internode of a matured plant

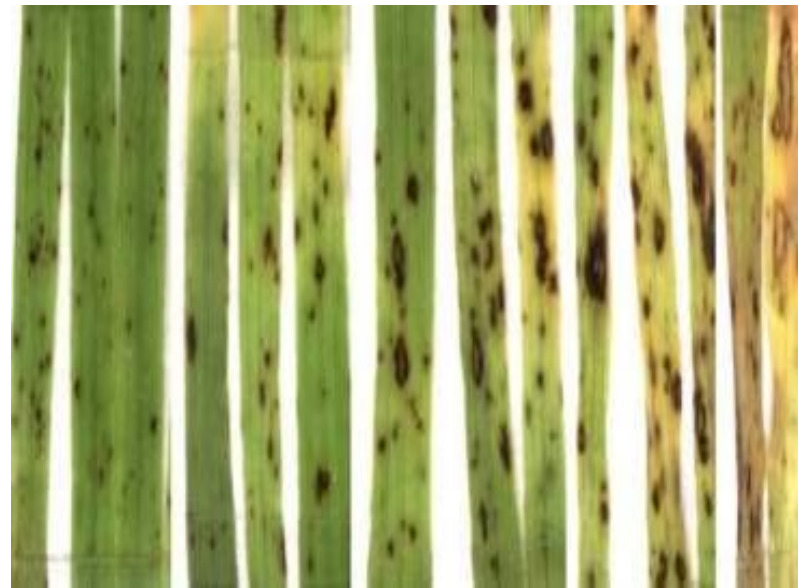

(a)

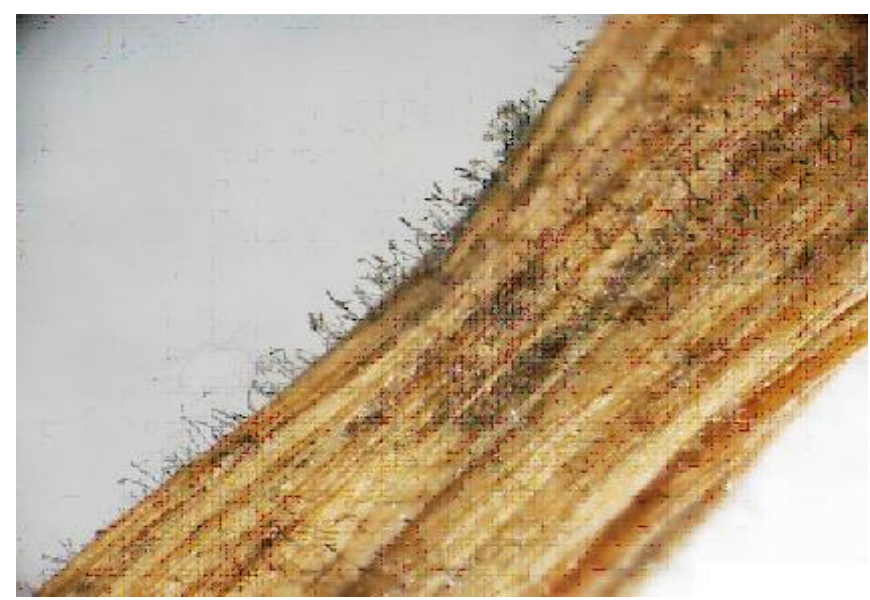

(b) 


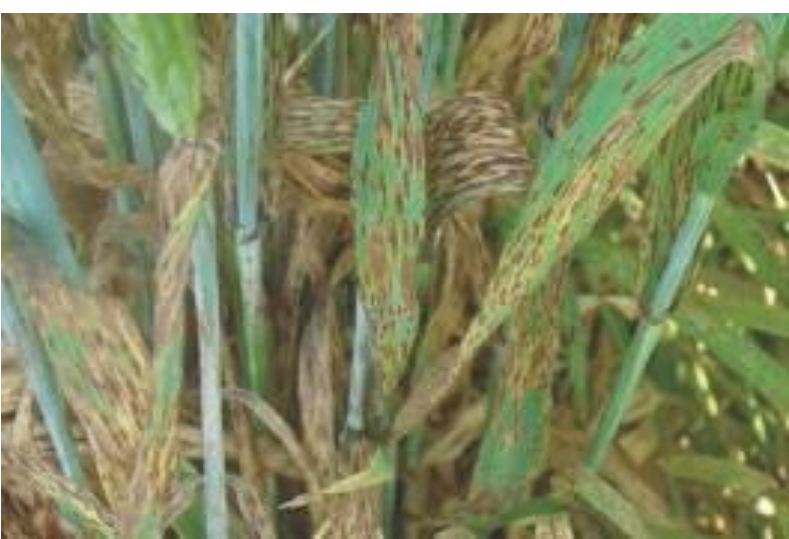

(c)

FIG:1: EFFECT OF MEDIA ON COLONY DIAMETER

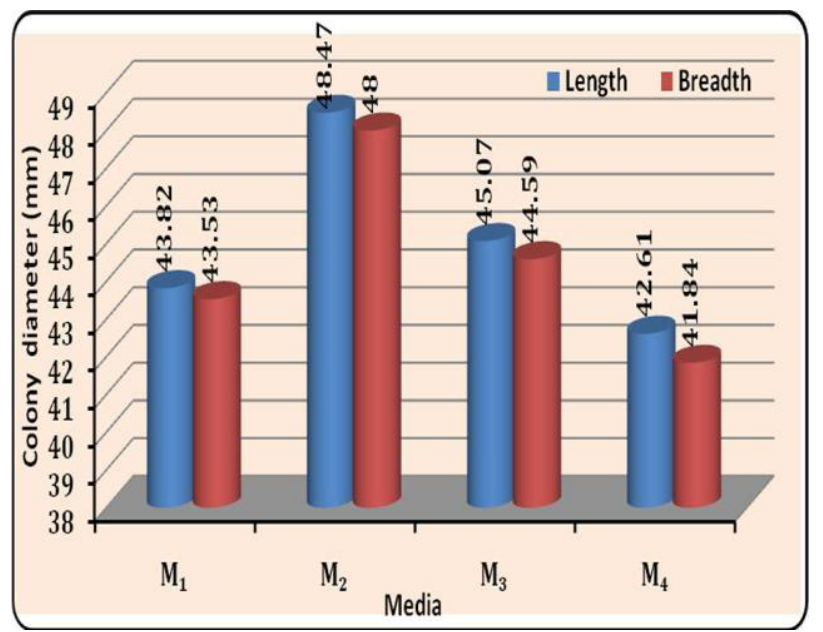

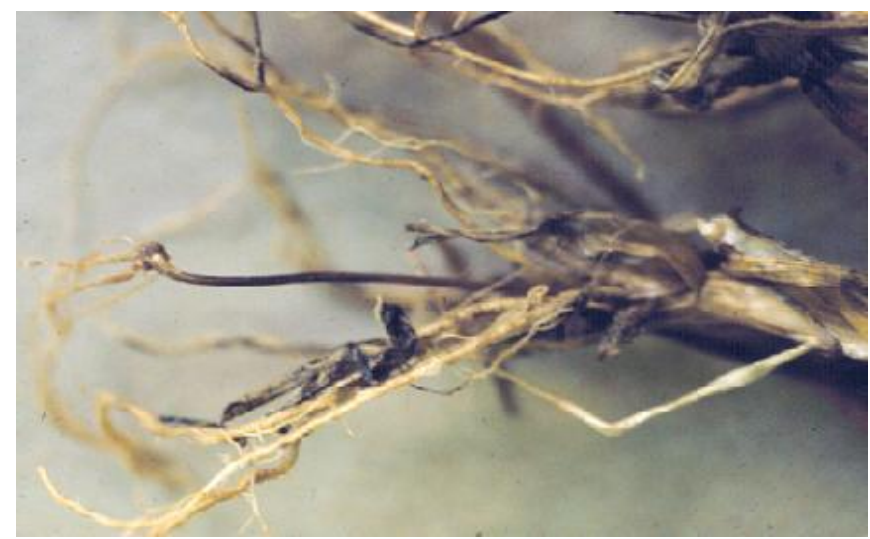

(d)

FIG:2: EFFECT OF DAYS ON COLONY

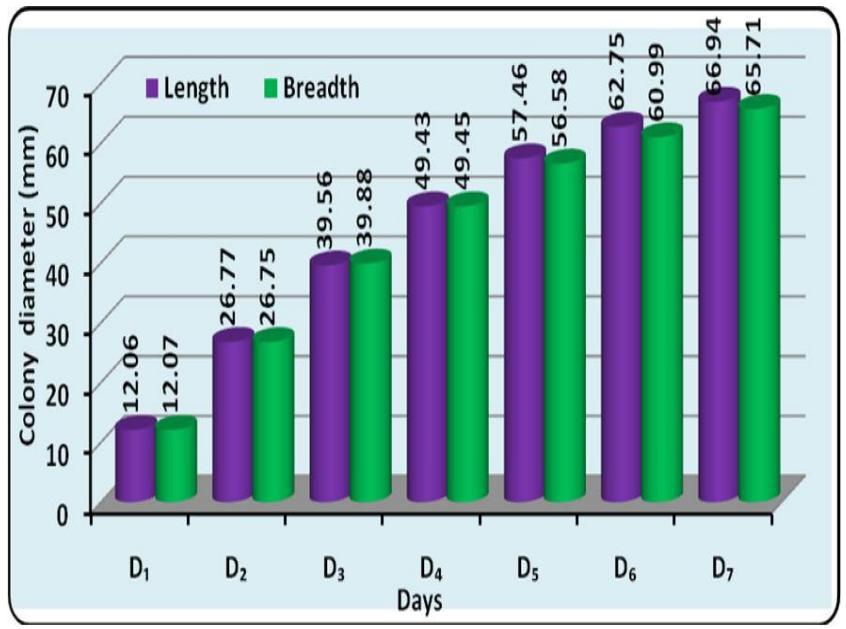

Fig.3 Effect media on spore morphology

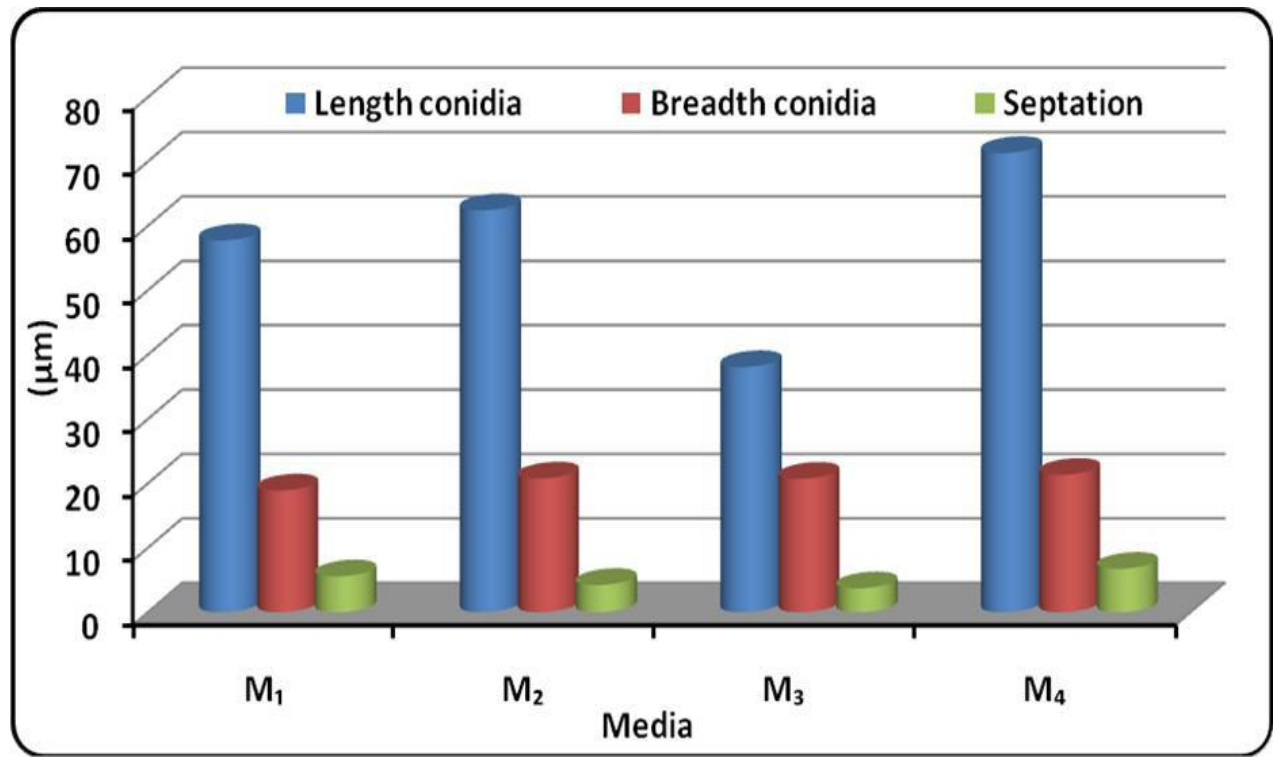


Fig.4 Effect of isolates on spore morphology

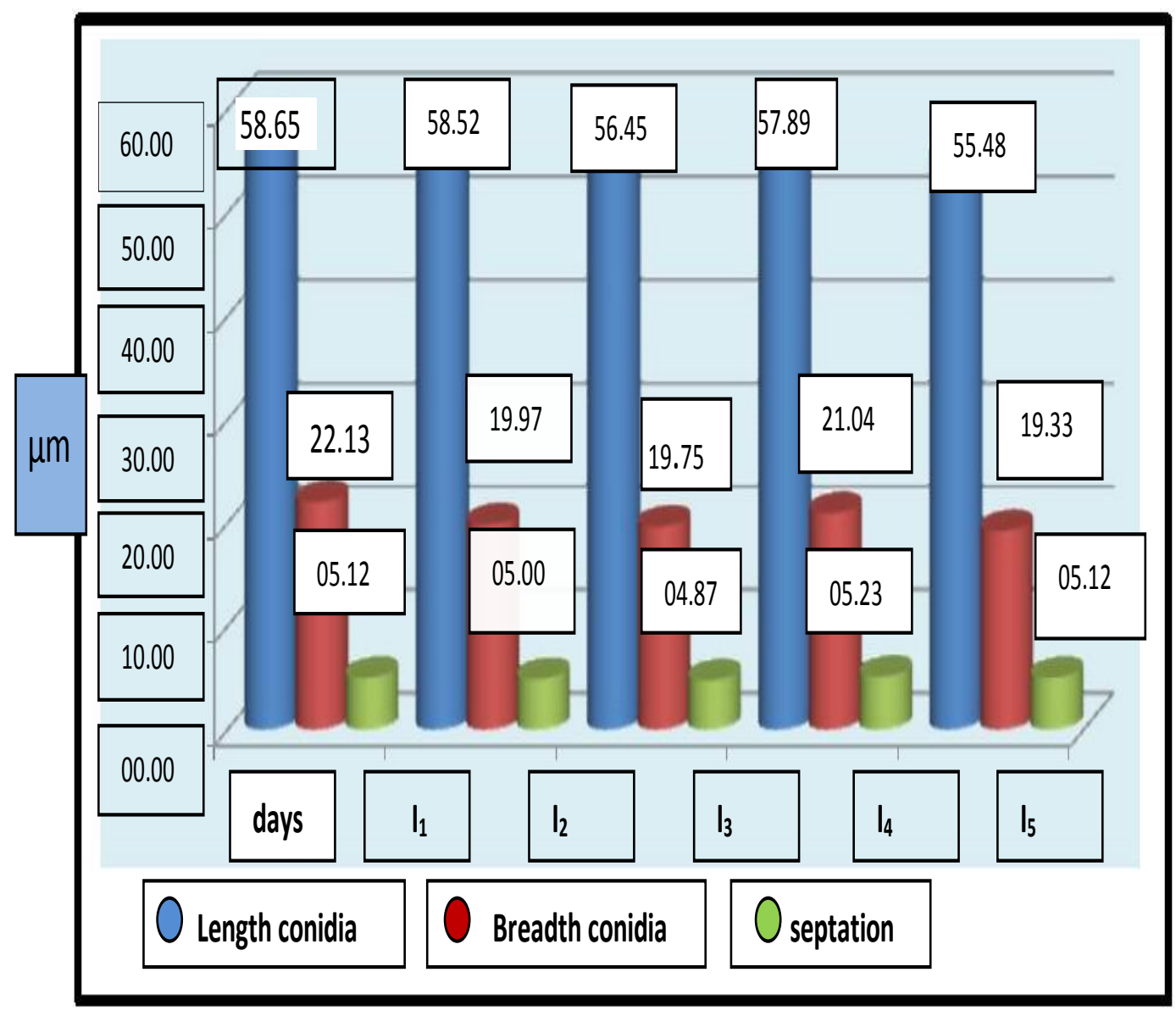

Plate.1 Morphological characteristics of spores (conidia) of different isolates of Bipolaris sorokiniana in PCA media. (A) I1 Alipurduar (B) I2DWR (C) I3 Pundibari (D) I4 Kisanganj (E) I5 Kalyani

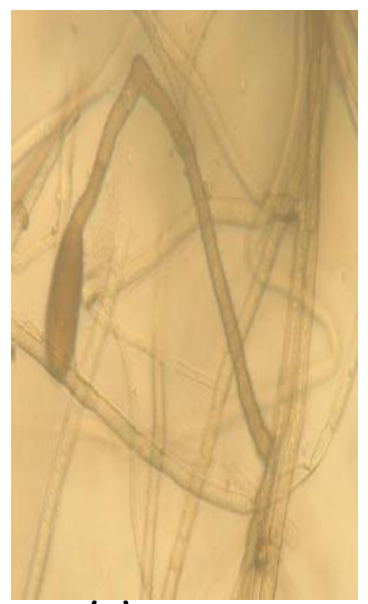

(A)

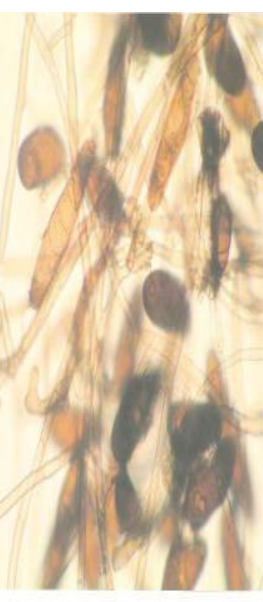

(B)

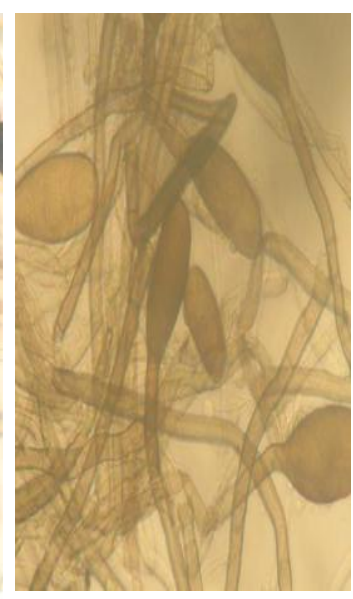

(c)

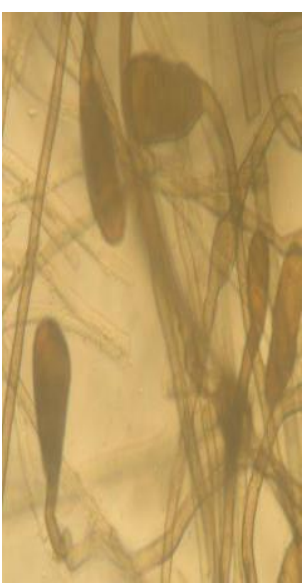

(D)

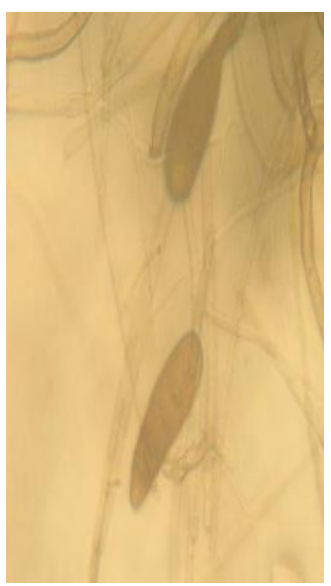

(E) 
Plate.2 Morphological characterization of spores of different isolates of Bipolaris sorokiniana in OMA media. (A), (B) and (C) conidia of I1 isolate; (D) conidia of I2 isolate; (E) hypha and conidia of I3 isolate; (F) conidia of I4 isolate; (G) bipolar germination of the spore, I3 isolate;

(H) spore of I5 isolate

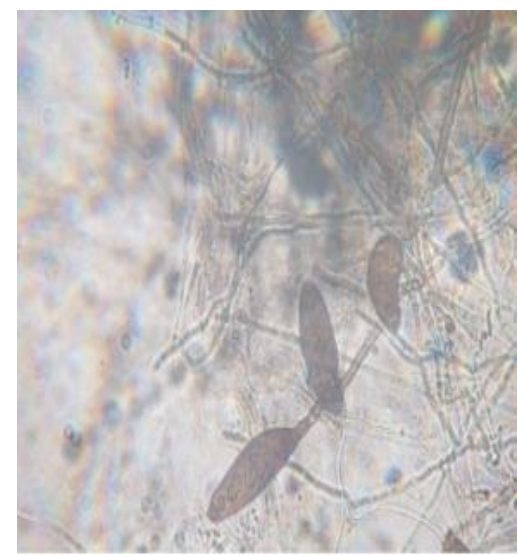

(A)

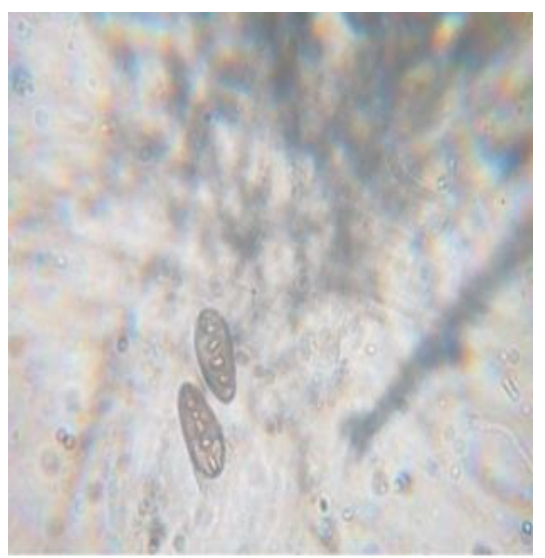

(B)

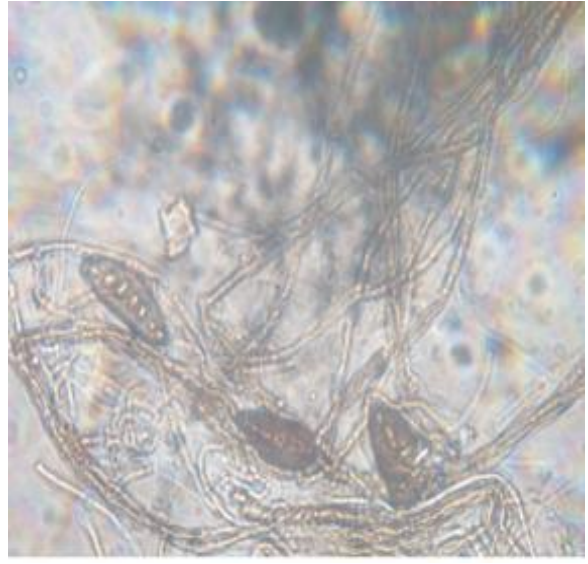

(C)

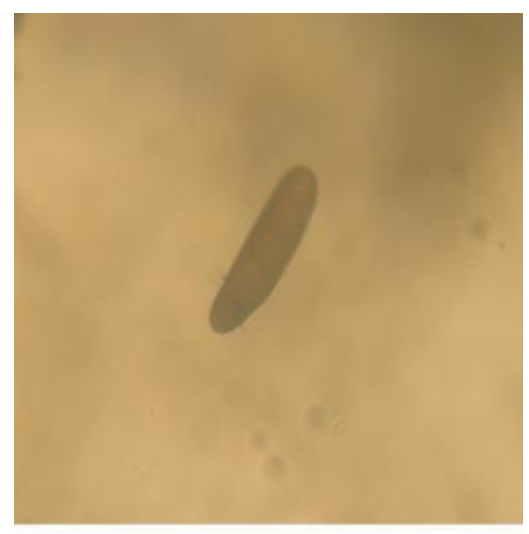

(D)

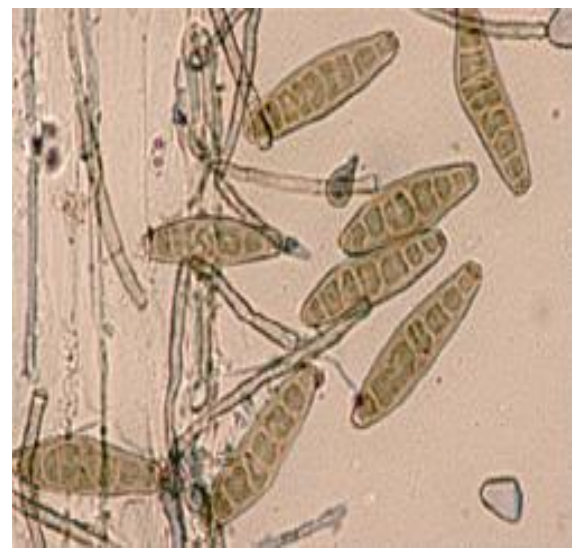

(F)

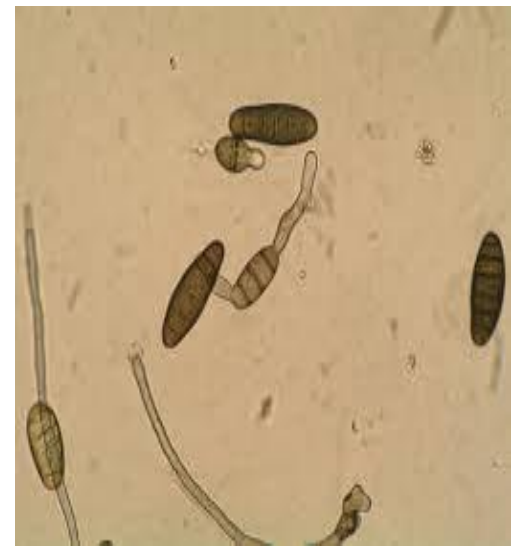

(G)

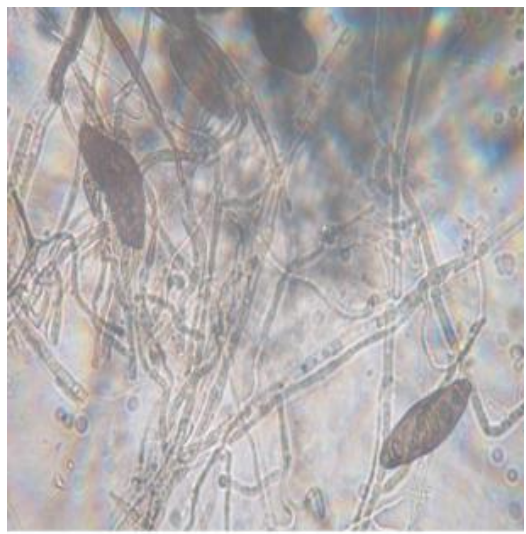

(E)

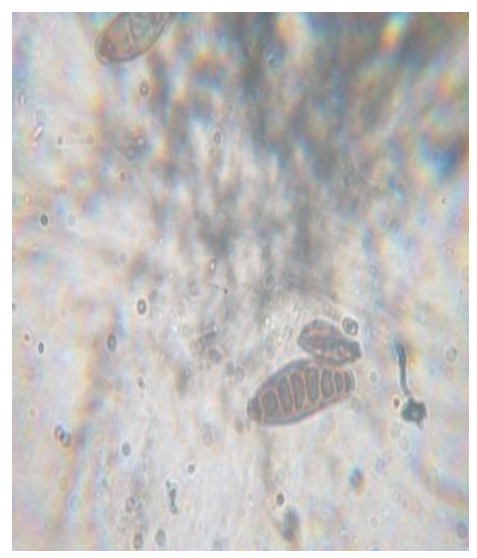

(H) 
Plate.3 Morphological characterization of spores (conidia) of different isolates of Bipolaris sorokiniana in CA media (A) B1; (B) germtube emerging from the outerwall of conidia of B1 isolate; (C) conidiophores with conidia B1 isolate; (D) B2 isolate; (E) germtube emergence of B2 isolate; $(\mathrm{F})$ conidiophores with conidia of B2 isolate; $(\mathrm{G}) \mathrm{B} 3$ isolate with hypha; $(\mathrm{H})$ and $(\mathrm{I}) \mathrm{B} 4$ isolate $(\mathrm{J}),(\mathrm{K})$ and $(\mathrm{L})$ conidia of B5 isolate

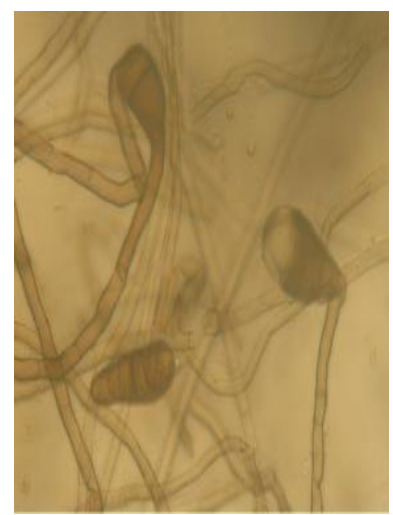

(A)
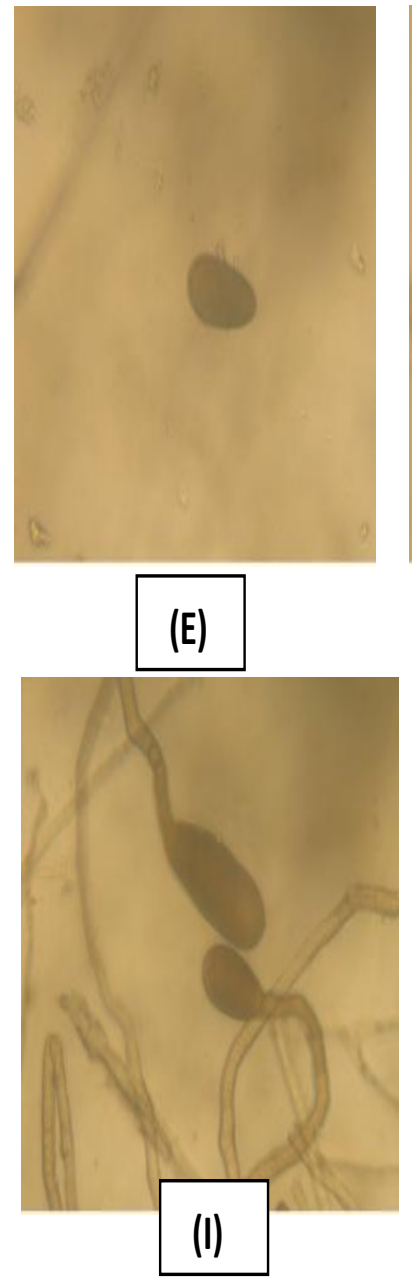

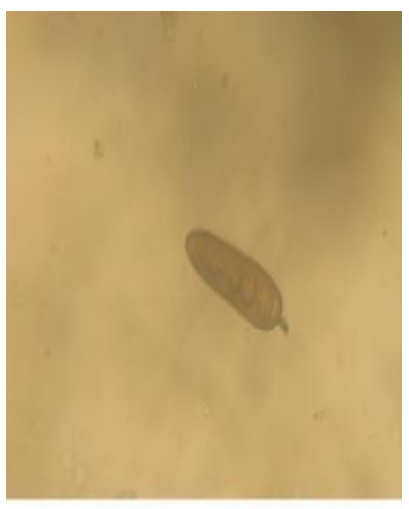

(B)

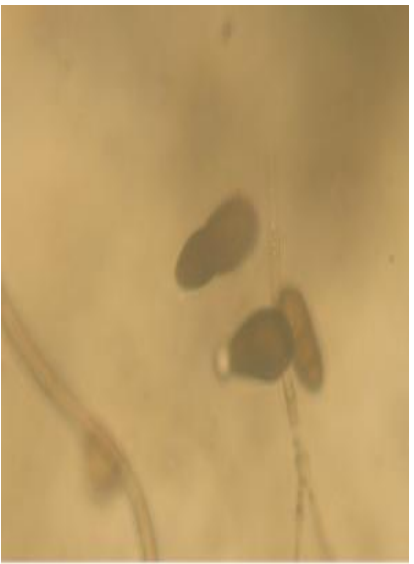

(F)

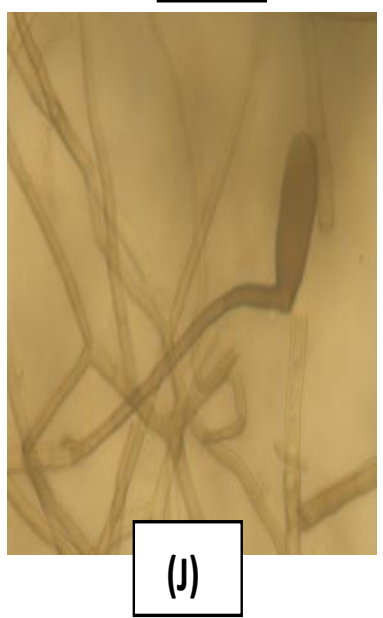

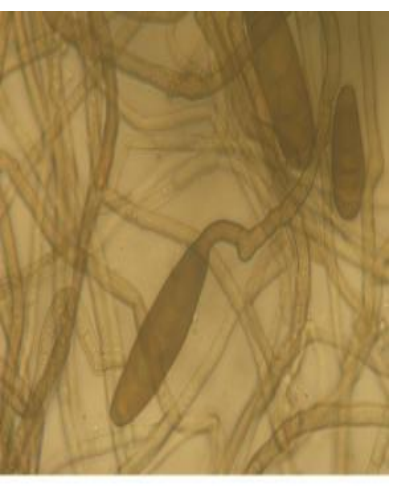

(C)

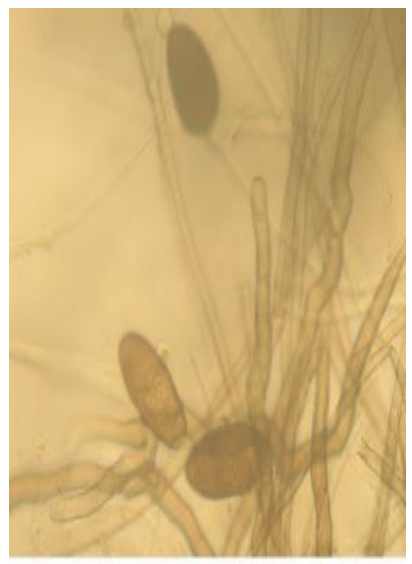

(G)

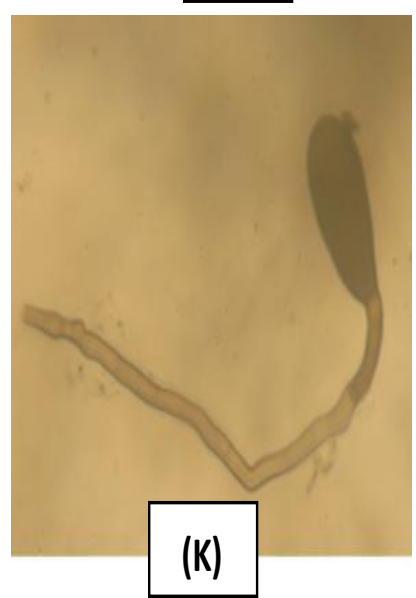

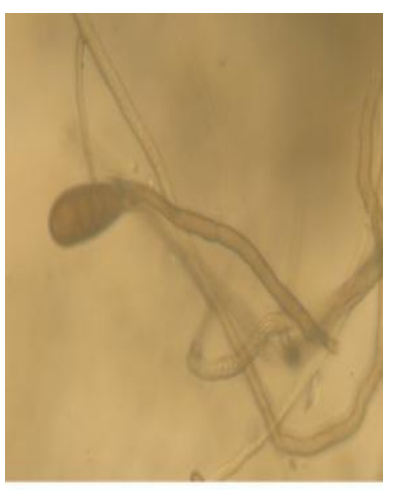

(D)
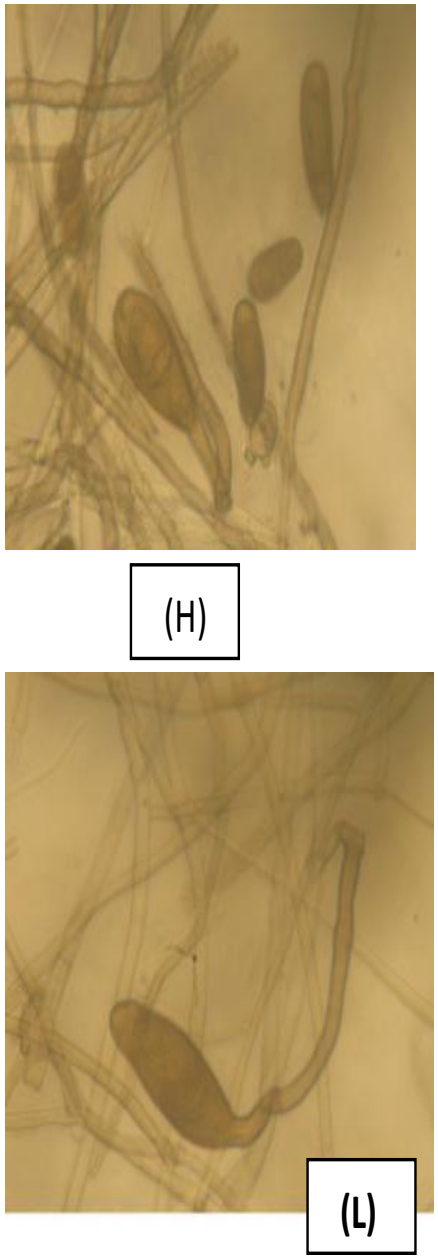
Plate.4 Conidial morphological characteristics in PDA media: (A) Alipurduar isolateI1 (B) DWR isolate I2 (C), (D) and (E) Pundibari isolate I3 (F) Kisanganj isolate I4 (G), (H) and (I) Kalyani isolate I5
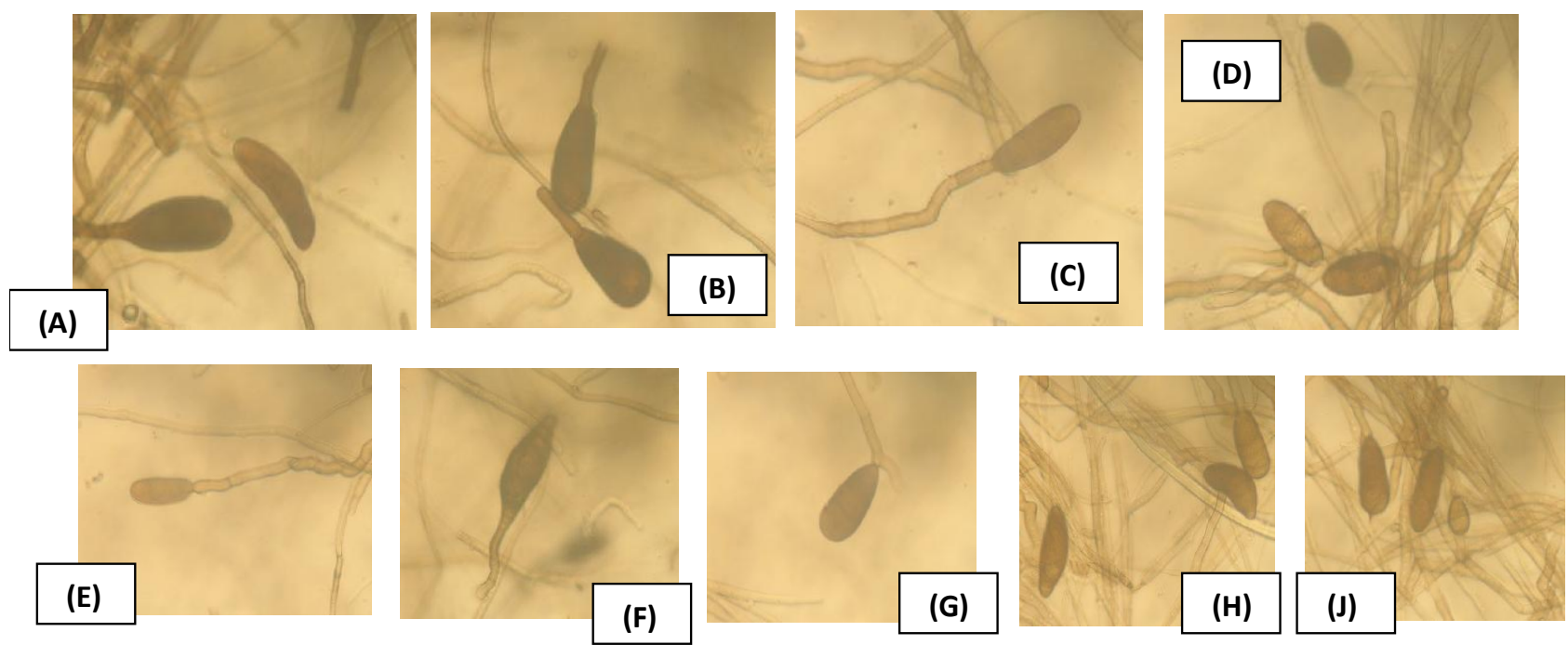

\section{Conidial structure (breadth)}

The breadth of the conidia was also different on different media by different isolates and their difference was statistically significant. Different isolates produced different breadth of conidia irrespective of different media used and their difference was statistically significant. Maximum width of conidia was obtained on Alipurduar isolate $(22.13 \mathrm{~mm})$ followed by Kisanganj isolate $(21.04 \mathrm{~mm})$ and their difference was statistically significant. Whereas DWR, Pundibari and Kalyani isolate showed no significant difference among themselves in respect to width of conidia grown on different media. Among them 4 media maximum breadth of conidia was obtained on PDA media $(21.35 \mathrm{~mm})$ statistically at par with OMA and CA medium irrespective of different isolates. Whereas minimum width of conidia was obtained on PCA media $(8.91 \mathrm{~mm})$ The interaction between Media and Isolate in respect to the width of conidia also showed different results and their difference were statistically significantly. Maximum breadth of conidia was obtained on PCA media $(22.80 \mathrm{~mm})$ from
DWR isolate followed by OMA $(22.64 \mathrm{~mm})$. Alipurduar isolate followed by PDA media $(22.05 \mathrm{~mm})$ by DWR isolate and their difference was not statistically significant. Minimum breadth of conidia was obtained by Kalyani isolate on PCA media $(17.80 \mathrm{~mm})$ and their difference was statistically different (Table 5; Fig. 3 and 4).

\section{Conidial structure (Septation)}

The septation of the conidia was also different on different media produced by different isolate and their differences were statistically significant. Among 5 isolates maximum septation was obtained from Kisanganj isolates $(5.23 \mathrm{~mm})$ and minimum in Pundibari Isolate though the difference between septation among the isolates showed no statistical significant results. The septation of isolates among the 4 media were different and their difference was statistically significant. Maximum septation was obtained on PDA media $(6.75 \mathrm{~mm})$ followed by PCA media $(5.57 \mathrm{~mm})$ irrespective of isolates and their difference was statistically significant. Minimum septation was obtained from Carrot 
Agar media $(3.72 \mathrm{~mm})$ followed by OMA $(4.23 \mathrm{~mm})$ and their difference were statistically significant. The interaction between Media and Isolate on septations were also statistically significant. Maximum septation was obtained from PDA media by Kalyani isolate $(6.67 \mathrm{~mm})$ followed by Kisanganj isolate $(7.07 \mathrm{~mm})$ on the same media. The isolate of Alipurduar and DWR also produce statistically at par septation on PDA media and also on PCA media. The minimum septation was located from CA media $(3.73 \mathrm{~mm})$ by Kisanganj isolate and Pundibari isolate followed by the same isolate on OMA (Table 6; Fig. 3 and 4).

Variability among isolates of Bipolaris sorokiniana was determined based on morphological characters of conidia (Kumar et al., 2002). The conidia of Bipolaris sorokiniana isolated from different agroecological regions of wheat and investigated their differences in conidial morphology and colony diameter on different media on different days after inoculation. The result showed that the isolates of Bipolaris sorokiniana produced similar type of symptoms when inoculated individually. The size of colony (length and breadth) was increased with increasing incubation period. Different media produces different growth characteristics (Colony diameter) on different media and Carrot Agar media produces highest colony diameter whereas minimum in Potato Dextrose Agar media in every days after inoculation among the four media used. It was also observed that all the isolates produced maximum growth in 7th old culture irrespective of media used. Maximum growth was obtained from DWR isolate on CA medium from 7th day old culture. Different isolates produced different type of conidial morphology on different media particularly length, breadth and septation of conidia. Among the four media PDA media produced maximum length, breadth and septation of the conidia $(71.33 \times 21.35$ with 6.75 septation) Among the isolates Alipurduar isolate $\left(\mathrm{I}_{1}\right)$ produced maximum length, breadth and septation of the conidia $(58.65 \mu \mathrm{m}, 22.13 \mu \mathrm{m}$ with 5.12 septation) irrespective of media used. So, it can be concluded from this experiment that Bipolaris sorokiniana isolates execute very few morphological variables among themselves. The most reliable technique is DNA technology but before using this technique the pathogenic aggressiveness of the isolates is most important criterion for future research work of this pathogen.

\section{References}

Kumar, J., P. Schafer, R. Huckelhoven, G. Langen, H. Baltruschat, E. Stein, N. Subramanian, K.H. Kogel, J. Kumar and S. Nagarajan. (2002). Bipolaris sorokiniana, a cereal pathogen of global concern: cytological and molecular approaches towards better control. Molecular Plant Pathology. 3 (4): 185195.

Malik, -V-K; Singh, -D-P and Panwar, -M-S. (2008). Losses in yield due to varying severity of spot blotch in wheat. IndianPhytopathology.61 (4): 526-527

Nagarajan, S. and J. Kumar. (1998). Foliar blight of wheat in India: Germplasm Improvement and future challenges for sustainable, high yielding wheat production. In: Helminthosporium blights of wheat: Spot blotch and Tan spot. (Eds.): E. Duveiller, H.J. Dubin, J. Reeves and A.

Nema KG and Joshi LH. (1973). Spot blotch disease of wheat in relation to host age, temperature and moisture. Indian Phytopathol.26:41-48

Prabhu AS, Singh A, (1974), Appraisal of yield loss in wheat due to foliage diseases caused by Alternaria triticina and Helminthosporium sativum. Indian 
Phytopathology, 27:632-634

Singh, S. K., Srivastava, K. D. and Singh, D. V. (2004). Pathogenic behaviour of leaf blight organisms on wheat. Indian Phytopathology Vol. 57 No. 3 pp. 319322

Swaminathan. (2000). One Man's Quest for a Hunger-Free World. Education
Development Center, Inc. pp 95 Uddin, -S-A; Khalequzzaman, -K-M and Rashid, -A-Q-M-B. (2006). Effect of relative humidity on the development of head blight by Bipolaris sorokiniana in wheat. Journal-of-Agriculture-andRural-Development-Gazipur; 4 (1/2): 61-65

\section{How to cite this article:}

Ankita Biswas and Srikanta Das. 2018. Morphological Characterization of Bipolaris sorokiniana Infecting Wheat. Int.J.Curr.Microbiol.App.Sci. 7(08): 225-248.

doi: https://doi.org/10.20546/ijcmas.2018.708.029 